\title{
Site Preparation Severity Influences Lodgepole Pine Plant Community Composition, Diversity and Succession Over 25 \\ Years
}

\begin{tabular}{|c|c|}
\hline Journal: & Canadian Journal of Forest Research \\
\hline Manuscript ID & cjfr-2017-0142.R1 \\
\hline Manuscript Type: & Article \\
\hline Date Submitted by the Author: & 20-Aug-2017 \\
\hline Complete List of Authors: & $\begin{array}{l}\text { Haeussler, Sybille; Skeena Forestry Consultants; University of Northern } \\
\text { British Columbia } \\
\text { Kaffanke, Torsten; T. Kaffanke Consulting } \\
\text { Boateng, Jacob; (retired) BC Ministry of Forests, Lands and Natural } \\
\text { Resource Operations, Resource Practices Branch } \\
\text { McClarnon, John; (retired) BC Ministry of Forests, Lands and Natural } \\
\text { Resource Operations, Forest Practices Branch } \\
\text { Bedford, Lorne; BC Ministry of Forests, Lands, and Natural Resource } \\
\text { Operations, Resource Practices Branch }\end{array}$ \\
\hline Keyword: & $\begin{array}{l}\text { silviculture, biodiversity, invasive species, Pinus contorta, ecological } \\
\text { disturbance }\end{array}$ \\
\hline $\begin{array}{r}\text { Is the invited manuscript for } \\
\text { consideration in a Special } \\
\text { Issue? : }\end{array}$ & N/A \\
\hline
\end{tabular}


1 Site Preparation Severity influences Lodgepole Pine Plant Community Composition, Diversity and

\section{Succession over 25 years}

4 Sybille Haeussler ${ }^{1}$, Skeena Forestry Consultants and University of Northern British Columbia, Smithers, BC.

5 Torsten Kaffanke, Torsten Kaffanke Consulting, Vanderhoof, BC. torsten_k@telus.net

6 Jacob O. Boateng, Resource Practices Branch, BC Ministry of Forests, Lands and Natural Resource

$7 \quad$ Operations, Victoria, BC (retired). jacob.boateng@gmail.com

8 John McClarnon, Resource Practices Branch, BC Ministry of Forests, Lands and Natural Resource Operations,

$9 \quad$ Victoria, BC (retired). John@veged.ca

10 Lorne Bedford, Resource Practices Branch, BC Ministry of Forests, Lands and Natural Resource Operation,

11 Victoria, BC. Lorne.Bedford@gov.bc.ca

12

13 'Corresponding author: 2041 Monckton Rd., Smithers, BC, Canada, V0J 2N4. Phone/fax: 250-847-6082;

14 Sybille.Haeussler@unbc.ca 
15 Site Preparation Severity influences Lodgepole Pine Plant Community Composition, Diversity and

\section{Succession over 25 years}

17 Abstract

18 Lodgepole pine ecosystems of central British Columbia face cumulative stresses and management practices are increasingly scrutinized. We addressed tradeoffs between "light-on-the-land" versus more aggressive

20 silvicultural approaches by examining plant communities and indicator species (non-natives, berry-producers,

21 epiphytes, mycotrophs, pine rust alternate hosts) across a gradient of 5-6 site preparation treatments at the

22 Bednesti trial (established 1987). We tested whether more severe site preparation (1) caused plant community

23 composition to diverge from a 35-46-yr-old reference forest; (2) accelerated succession by hastening crown

24 closure; or (3) delayed succession by promoting seral species. Non-metric multi-dimensional scaling (NMDS)

25 ordination showed all treatments converging toward the reference forest composition. At $10 \mathrm{yr}$, succession was

26 incrementally delayed by more severe treatments; at $25 \mathrm{yr}$, only burned windrows were still delayed. Mixed

27 effects models based on site preparation severity were better than crown closure models for 11 of 13 variables

28 tested, suggesting belowground processes mostly drive succession in these infertile ecosystems. Invasive

29 hawkweeds persisted on all treatments at $25 \mathrm{yr}$. Limited, contradictory data did not support using mechanical or

30 fire treatments to reduce alternate hosts of pine stem rusts. Long-term trials like Bednesti highlight the need for

31 ecosystem-specific strategies and diverse approaches to accommodate conflicting benefits and risks of

32 disturbance in forests.

33 Key words: silviculture, biodiversity, ecological disturbance, invasive species, Pinus contorta 
34

35

\section{Introduction}

Lodgepole pine (Pinus contorta var. latifolia) forests dominate the plateau landscape of the central interior of British Columbia (BC), Canada. Over the past 50 yr this landscape has come to represent the heartland of BC's forest industry as lodgepole pine supplanted Douglas-fir (Pseudotsuga menziesii) and interior spruce (Picea glauca $x$ engelmannii) as the dominant tree harvested and replanted ${ }^{1}$. Formerly, silviculturists viewed lodgepole pine ecosystems as resilient and relatively problem-free. This perception has changed in the 21 st Century as BC's great mountain pine beetle (Dendroctonus ponderosae) outbreak (Shore et al. 2004) coincided with other stresses on lodgepole pine forests, including a growing incidence of stem and foliar diseases (Woods et al. 2017), large wildfires (Ghoussoub 2017) and timber supply shortages (Burton 2010), as well as regional declines in woodland caribou (Rangifer tarandus caribou) populations (Cichowski and Williston 2005). One outcome of the confluence of forest management challenges is that silvicultural practices in lodgepole pine forests are now subject to increased professional and public scrutiny.

We revisited the Bednesti experiment, a 25-yr old well-replicated, randomized silvicultural site preparation trial established in 1987 on an infertile upland site typical of central BC (Bedford and Sutton 2000). Its objective was to improve understanding of biological and management factors affecting lodgepole pine establishment and growth, and to devise management strategies to improve productivity, principally through use of mechanical site preparation equipment. Our current study examines the composition, diversity and dynamics of plant communities (vascular plants, bryophytes, macrolichens) in the experiment and an adjacent unmanaged reference forest with the aim of addressing tradeoffs in managing timber and non-timber resources in these increasingly stressed forest ecosystems.

The replicated, randomized design and range of alternative forest disturbances included at Bednesti and a partner study site in northeast BC have provided outstanding opportunities to explore questions related to resilience and restoration success in northern forests (Haeussler et al. 1999, 2002, 2004). Here, we explore 
57 how initial disturbance severity interacts with subsequent tree growth and crown closure to influence community

58 composition and diversity, as well as the abundance of culturally and ecologically significant plants (edible

59 berries, epiphytes, late seral herbs) or plants that pose risks to biodiversity and forest health. The latter include

60 invasive non-native plants -notably hawkweeds of the Pilosella subgenus (Wilson 2006), and alternate (telial)

61 hosts of two rusts that kill and damage lodgepole pine, comandra blister rust (Cronartium comandrae) and

62 stalactiform blister rust (Cronartium coleosporioides) whose respective alternate hosts in central BC are false

63 toadflax (Geocaulon lividum) and herbs of the broomrape family (Orobanchaceae).

64 We proposed three alternative hypotheses regarding successional trajectories:

65 H1: Silvicultural site preparation alters lodgepole pine plant community successional trajectories, causing single point in time.

\section{Methods}

80

Bednesti study area: Bednesti (53052' N, 123029'W, 825 m elev.) is located in central BC, 50 km west of 
81 Prince George, in the dry, warm subzone of the Sub-Boreal Spruce biogeoclimatic zone and is intermediate

82 between the Lodgepole Pine-Black Spruce-Feathermoss (SBSdw3/05) and Interior Spruce-Pink Spirea-Prickly

83 Rose (SBSdw3/01) site series (Delong et al. 1993). Estimated mean annual temperature is $3.4^{\circ} \mathrm{C}$ with $595 \mathrm{~mm}$

84 precipitation and $231 \mathrm{~mm}$ snow (Wang et al. 2012). The gently undulating terrain (<10\% slope) is a compact basal till with scattered pockets of sand and gravel. Soils are Podzolic to Brunisolic Gray Luvisols with 3-6 cm thick organic horizons (LFH) (Soil Classification Working Group 1998), sandy loam to silt loam surface texture and $10-65 \%$ coarse fragments. A compact horizon at $10-50 \mathrm{~cm}$ depth restricts tree rooting, causing soils to be excessively wet in spring and drought prone in late summer

The sub-boreal plateau of central BC has a history of stand-replacing wildfires with $80-125 \mathrm{yr}$ return intervals (Delong and Tanner 1996) and recurrent outbreaks of mountain pine beetle. Cattle graze widely, but the study site was not regularly or recently grazed due to sparse forage. The primary human use was most likely blueberry-picking. In 1960, Bednesti supported mature wildfire-origin lodgepole pine with a subcanopy of black spruce (Picea mariana) and interior spruce. The understory was dominated by velvet-leaved blueberry (Vaccinium myrtilloides), bunchberry (Cornus canadensis) and red-stemmed feathermoss (Pleurozium schreberi). It was strip logged in 1963-64. Leave strips were removed in 1971. A 1986 survey found insufficient 96 conifer stocking.

97 Experimental design and treatments: Vegetation was sheared and piled in long windrows with a brush blade mounted on a D8 crawler tractor in winter 1986-87. Snowpacks and frozen ground minimized soil disturbance.

99 Treatment plots measuring $\sim 30 \mathrm{~m} \times 25 \mathrm{~m}$ were laid out between windrows, avoiding wet and excessively disturbed areas. Neighbouring plots were grouped into five blocks. Five (1997, $10 \mathrm{yr})$ or six $(2012,25 \mathrm{yr})$ of 10 site preparation treatments tested at Bednesti were selected for vegetation sampling to encompass a gradient from low to high disturbance severity: on snow, creating little soil exposure and leaving LFH layers, budbanks and seedbanks mostly undisturbed. Severity ranking: low. 
DT: Disk Trenching. After shearing (see SH), a TTS Delta powered disk trencher mounted on a rubbertired skidder created continuous shallow, linear furrows spaced $3 \mathrm{~m}$ apart. Mineral soil was $48 \%$ exposed with LFH, budbanks and seedbanks buried or coarsely mixed. Severity ranking: moderately low.

CM: Coarse Mixing. After shearing, an Eden relief bedding plow with 6 hydraulic disks mounted on a crawler tractor created $1.6 \mathrm{~m}$ planting beds flanked by $50 \mathrm{~cm}$ trenches of exposed subsurface soil. In raised beds, intact LFH was buried beneath loose chunks of soil and organic matter. Mineral soil exposure was $\sim 100 \%$ with budbanks and seedbanks buried, uprooted and coarsely mixed. Severity ranking: medium. PI: Plowed and Inverted (sampled at 25 yr only). After shearing, a three-bottom agricultural breaking plow mounted on a crawler tractor created side-by-side inverted furrow slices. Mineral soil exposure was 100\% with LFH, budbanks and seedbanks inverted and buried under $10-15 \mathrm{~cm}$ of soil. Severity ranking: medium. FM: Fine Mixing. A high-speed rotating drum (Madge Rotoclear) pulled behind a crawler tractor created 15 $\mathrm{cm}$ of finely chopped organic matter intimately mixed with soil. Mineral soil exposure was $100 \%$ with most roots and rhizomes finely comminuted. Severity ranking: high. For logistical reasons, these plots were grouped at the south end of the site.

BW: Burned Windrow. After shearing, slash was piled in long rows and burned. LFH, fine and medium slash were completely consumed forming a thick ash layer. Mineral soil exposure was minimal, but budbanks and seedbanks to $10-15 \mathrm{~cm}$ depth were consumed by intense heat. Plots were laid out in wellburned $10 \mathrm{~m} \times 50 \mathrm{~m}$ strips adjacent to each block. Severity ranking: high.

RF: Reference Forest. In 2012, we located 5 unmanaged naturally-regenerated forest plots immediately north of the Bednesti experiment. RF plots were assigned to the block situated directly south on ecologically similar soils. We cored several dominant trees in each plot and found that two were $\sim 35 \mathrm{yr}$ old and three were $\sim 46$ yr old, corresponding to natural regeneration after the 1963-4 and 1971 two-pass strip logging operation. We were unable to use a mature, wildfire origin stand as a reference area, because all mature pine on comparable soils near Bednesti were killed by mountain pine beetles and subsequent salvage logging. RF plots had rare beetle mortality and represented the oldest live lodgepole pine stand in the local area.

Site preparation was carried out late in 1987. In spring 1988, 80 one-yr-old Styroblock ${ }^{\text {TM }}$ PSB 211 lodgepole pine seedlings were planted in each treatment unit at a target density of 1200 stems ha $^{-1}$ with 48 inner seedlings serving as measurement trees surrounded by an outer ring of 32 unmeasured buffer trees. Tree spacing averaged $2.9 \mathrm{~m} \times 2.9 \mathrm{~m}$, but exact spacing varied with the configuration of planting spots in each 
136

treatment.

SH, DT, CM and PI treatments were randomly assigned to plots within blocks. BW, FM and RF plots were assigned to the closest block of other treatments. The experimental area was topographically uniform with no systematic soil or vegetation gradient. Haeussler et al. (1999) found no evidence of a block effect, and concluded the largest source of pre-treatment variation in plant community composition was the distribution of small patches of trembling aspen (Populus tremuloides) or green alder (Alnus viridis) scattered independently of blocks across the site.

Vegetation sampling: 10-yr vegetation sampling took place August 16-27, 1997; 25+-yr sampling from August 14-25, 2012. Except as noted, identical methods were used on both dates. All plant identification and ocular estimates were made by the senior author. In 25 plots at $10 \mathrm{yr}$ (SH, DT, CM, FM, BW) and 35 plots at 25+ yr (SH, DT, CM, PI, FM, BW and RF), we randomly located 3 vegetation subplots. Subplots were positioned centrally within the narrow burned windrows (BW) to minimize edge effects. Ten-yr subplots were unmarked and a new randomization was done at $25 \mathrm{yr}$. Each subplot was a nested set of rectangular quadrats to sample four vegetation layers: (i.) tall shrubs and trees $>2 \mathrm{~m}$ height $(5 \mathrm{~m} \times 5 \mathrm{~m})$; (ii.) low shrubs and trees $<2 \mathrm{~m}$ height (3 $\mathrm{m} \times 3 \mathrm{~m})$; (iii.) herbs and dwarf shrubs $(1 \mathrm{~m} \times 3 \mathrm{~m})$; (iv.) forest floor mosses, liverworts and macrolichens (1 $\mathrm{m} \times 1 \mathrm{~m}$ in 1997; $0.33 \mathrm{~m} \times 3 \mathrm{~m}$ in 2012). An ocular estimate of percent cover was recorded for each species (or taxon, Appendix I). At $10 \mathrm{yr}$, to aid in quantifying treatment severity, we recorded the surface area $\%$ of mineral soil, rocks and stones, organic matter and woody debris on each $3 \mathrm{~m} \times 3 \mathrm{~m}$ quadrat and \% disturbed vs. undisturbed ground area.

At 25+ yr, we spent 20-30 minutes recording occurrence of mycoheterotrophic and mixotrophic species (hereafter, mycotrophs) within the "measurement area" (defined below) of each plot. Mycotrophs are vascular plants in the Orchidaceae, Pyrolaceae, Monotropaceae, Lycopodiaceae and Botrychiaceae that obtain all or some of their nutrition from mycorrhizal connections to conifers and other forest plants (Massicotte et al. 2012). Among vascular plants of northern forests, this functional group is the most sensitive to tree cutting and forest 
160 floor disturbance (Haeussler et al. 2007). We also sampled epiphytic macrolichens, liverworts and mosses on 5

161 randomly selected pines per plot. All epiphytes located on the trunk below breast height and on three $10-\mathrm{cm}$

162 sections (proximal, distal and mid portion) taken from three random branches radially distributed around the

163 trunk below breast height were collected and identified to species or sub-genus in the laboratory.

164 Total height and diameter at breast height were recorded for each lodgepole pine sample tree from 11 to 25

165 yr after planting (at $10 \mathrm{yr}$, basal diameter was measured). The "measurement area" of each plot was

166

167

168

169

170

171

172

173

174

175

176

177

178

179

180

181

182

183

determined by stem-mapping the perimeter defined by points of origin of the outer ring of measurement trees,

then extending the boundary 1.5 m outward to encompass tree crowns. These data were used to calculate mean height, mean diameter and basal area per hectare for each experimental plot at 10 and $25 \mathrm{yr}$. We extrapolated backward one yr from the 11- to 25-yr curves to obtain $10 \mathrm{yr}$ diameters. For RF plots we used the mean diameter and height of the 5 epiphyte sample trees and a prism sweep to determine basal area. We estimated stem volume per hectare as (basal area x height)/3 and the crown volume index as (mean percent cover of pine)x(mean height). Pine health was surveyed 12 times between $7 \mathrm{yr}$ and $25 \mathrm{yr}$ on four treatments only (SH, DT, CM, BW). The cumulative number of trees that died from rust infection or had detectable rust cankers on or within $10 \mathrm{~cm}$ of the main stem by $25 \mathrm{yr}$ was tallied by plot separately for comandra blister rust (C$R U S T)$ and stalactiform blister rust (S-RUST).

Data analysis: We used multivariate analysis of plant community composition and mixed effects modeling of individual response variables to test the hypotheses over gradients of site preparation severity, tree size and crown closure. To evaluate $\mathrm{H} 1$ vs. H2-3, we examined multivariate and univariate indicators of plant composition for evidence of diverging vs. converging successional trajectories. Divergence was defined throughout as an increase in the Bray-Curtis Distance (BCD) between two plant communities with time; convergence as a decrease in $\mathrm{BCD}$. To test $\mathrm{H} 2$ vs. $\mathrm{H} 3$, we first determined if tree size and crown closure increased with site preparation severity, then evaluated if composition converged more rapidly at high $(\mathrm{H} 2)$ or low $(\mathrm{H} 3)$ severity. Next we determined whether tree size or crown closure $(\mathrm{H} 2)$ provided better model fits than severity $(\mathrm{H} 3)$ for 
184 185 186

187 188 189 190 191 192

195

univariate indicators. We also examined if higher severity increased richness and abundance of late $(\mathrm{H} 2)$ vs. early seral (H3) plant indicators.

explanatory variables (Table 1a): We scored the 7 treatments on an index of relative severity (after Roberts 2007):

$$
\begin{aligned}
& S=\left[V N_{\max }+F F / F F_{\max }\right] / 2 \\
& V=A G+B B+S B, \text { where } A G=\% \text { removal of above-ground vegetation; } \\
& \quad B B=\% \text { destruction of soil budbank; } S B=\% \text { destruction of soil seedbank. } \\
& \quad V_{\max }=\text { maximum score. }
\end{aligned}
$$
$F F=C W D+L F H+M S$, where $C W D=100-\%$ cover of woody debris relative to max; $L F H=\%$ removal of $L F H$ layer; $M S=$ alteration of top $10 \mathrm{~cm}$ of mineral soil relative to max.

$$
F F_{\text {max }}=\text { maximum score. }
$$

Scores for vegetation ( $V$ ) and forest floor (FF) components were estimated from written records, 1987-88 photos and 10-yr ground cover data. We also considered two binary alternatives to $S$ : a high severity threshold $(0=$ all unburned treatments; $1=\mathrm{BW})$ and a low severity threshold $(0=$ all site preparation treatments; $1=\mathrm{RF})$. The first axis of a principal components analysis (PCA) of lodgepole pine height, diameter, basal area ha-1, stem volume ha-1, $\%$ cover and crown volume index (representing $81 \%$ of total variation) served as an integrated index of pine size (PSIZE). Crown closure (CC) was estimated by summing \% cover estimates of lodgepole pine plus all other tree species of equal or greater height. Although few non-pine species occurred in the tree canopy, PSIZE and CC were only moderately correlated $(r=0.54)$ because PSIZE encompassed the entire plot (48 measurement trees) whereas $\mathrm{CC}$ was estimated on 3 randomly selected $5 \mathrm{~m} \times 5 \mathrm{~m}$ quadrats per plot. Other explanatory variables included plot geographic coordinates to test for spatial pattern, and \% cover of blister rust alternate hosts.

multivariate analysis: Non-metric multi-dimensional scaling (NMDS) with the vegan package in $R$ (Oksanen et al. 2017) was used for unconstrained ordination of plant community composition (\% cover of vascular plants, bryophytes and macrolichens with subplots pooled at the plot scale, 60 plots $\times 134$ taxa). 
210 Cover was subjected to a Wisconsin double standardization and square root transformation. BCD was selected

211 as the distance metric. We ran the ordination with $\mathrm{k}=1$ to 7 dimensions with maximum of 1000 random starts

212 to find a convergent solution. Stress levels and Shepard plots of the ordination distances against original

213 dissimilarities at $\mathrm{k}=1$ to 7 were used to choose the number of dimensions. We reran the NMDS several times

214 at the best $k$, beginning with the best previous solution, to find a stable configuration. The strength of fit $\left(r^{2}\right)$ and

215 significance level of explanatory variables (Table 1a) were determined by 999 Monte Carlo permutations. For

216 variables with $P<0.05$, correlation coefficients $(r)$ with individual NMDS axes were examined, and these

217 variables were overlain on the ordination.

218 univariate analysis: We fit linear mixed effects models with the nlme package in R (Pinheiro et al. 2015)

219 for each response variable (Table 1b). Subplot data were pooled at the plot scale and response variables were

220 normalized with a power transformation, as needed. Random effects were plot nested within block for models

221 encompassing 2 dates ( $n=50$ or 60 ); block only for one-yr models ( $n=25$ or 35$)$. These models are equivalent

222 to a Randomized Complete Block Design with a split plot for repeated measures in classical ANOVA. After

223 examining scatterplots, we worked our way through an appropriate set of full to reduced fixed effects models.

224 Severity was modeled as linear $(S)$, quadratic $\left(S+S^{2}\right)$ or cubic $\left(S+S^{2}+S^{3}\right)$ functions, with and without a $Y R$

225 intercept and $S \times Y R$ interaction terms, and with $B W$ or $R F$ substituting for $S$ (linear only). The best severity

226 model based on satisfactory distribution of residuals and lowest Akaike information criterion (AIC) was

227 compared to the best tree size/crown closure model with PSIZE or CC as linear, quadratic or cubic variables.

228 CC full models were identical to $S$ full models, but PSIZE models did not require YR intercepts or interaction

229 terms. For infrequent taxa (non-hawkweed invasives, TOAD), we substituted Kruskall-Wallis non-parametric

230 ANOVA (K-W; stats package, R Core Team 2017) to contrast appropriate combinations of treatments or years.

231 For count variables with many zeroes (C-RUST, S-RUST), we fit a poisson mixed effects model (Ime4 package

232 in R Version 1.1-12; Bates et al. 2015) without the low severity threshold (RF wasn't sampled for rusts) and

233 added \% cover of alternate hosts (Table 1a) as candidate fixed effects. 
234

235

236

\section{Results}

238

239

240

241

242

243

244

245

246

247

248

249

250

251

252

253

254

255

256

257

To evaluate ecological impacts of hawkweed invasion we examined correlations between hawkweed cover and the diversity (richness, evenness, Shannon's index) and cover of native herb species on $1 \mathrm{~m} \times 3 \mathrm{~m}$ quadrats at $10 \mathrm{yr}(\mathrm{n}=75)$ and $25 \mathrm{yr}(\mathrm{n}=105)$.

Tree size and crown closure: PSIZE and CC increased non-linearly with site preparation severity (Table 2i, Fig. 1). There was a moderate increase from low to medium severity but little additional increase to high severity (cf. Bedford and Sutton 2000, Boateng et al. 2012). Site preparation followed by planting clearly accelerated stand development because PSIZE in high severity treatments at $25 \mathrm{yr}$ was similar to reference forests at 35-46 yr, while CC in low severity treatments at $25 \mathrm{yr}$ and medium-high severity treatments at $10 \mathrm{yr}$ equaled that of reference forests.

Plant community composition: An NMDS with $k=3$ dimensions, stress $=0.137$ and Shepard plot $R^{2}=0.981$ (Table 3a) was selected. Neither blocks (goodness of fit $r^{2}=0.057 ; P=0.60$ ), nor geographic coordinates (Table 3b) were significantly correlated with the ordination, confirming our view that spatial gradients in terrain and pre-1960s vegetation were weak, and that treatments not randomly assigned to plots within blocks could reasonably be incorporated into the experimental design.

Differences in community composition related to stand age (or sampling date) greatly outweighed differences due to site preparation. NMDS Axis1 was strongly correlated with stand age and pine size $(r>0.9$, Table 3b) and cleanly separated 10-, 25-, 36-, and 46yr-old plant communities (vertical lines in Fig. 2a). NMDS Axis2 was highly correlated with severity and crown closure $(r<-0.89$, Table $3 b)$. Low severity treatments (RF, SH, DT) were located high on Axis2, medium-high severity treatments (CM, PI, FM) near centre, and burned windrows (BW) at the bottom in both yr (Fig. 2a). At 10 yr, BW was separate from all other treatments, but at 25 yr BW overlapped slightly with FM, and FM, PI, and CM were no longer distinct from SH and DT, indicating convergence. No significant explanatory variables were strongly correlated with Axis3 (Table 3b, not graphed). Successional trajectories proceeded laterally to the right in low severity and diagonally up and right in medium 
258

259

260

261

262

263

264

265

266

267

268

269

270

271

272

273

274

275

276

277

278

279

280

281

and high severity plant communities.

Ten yr plant communities (Fig. 2b, left) were characterized by pioneering native and non-native forbs (Epilobium ciliatum [Ec], Trifolium spp. [Tr], Hieracium spp. [Ha, Hp], Taraxacum officinale [To]), graminoids (Poaceae [Po, Fo], Carex spp. [CX], Juncus spp. [Ja, Je]) and pioneering bryophytes (Ceratodon purpureus [Cp], Polytrichum juniperinum [Pj]). Shade tolerant and mycotrophic forbs (Chimaphila menziesii [Cm], Orthilia secunda [Os], Goodyera repens [Gr], Linnaea borealis [Lb], Lycopodium spp.[Ld, La]), late seral feathermosses (Hylcomium splendens [Hs], Pleurozium schreberi [PI]), liverworts (Barbilophozia [Bh, Bl], Lophozia spp.[Lo]), and many epiphytic and Peltigera lichens [Lp, Pe] were associated with 25+ yr plant communities (Axis1, right). Species associated with higher site preparation severity, irrespective of stand age, included green alder [Av], trembling aspen [Pt], yarrow (Achillea millefolium [Ac]), white meadow-sweet (Spiraea betulifolia [Sb]) and fireweed (Epilobium angustifolium [Ea]) (lower Axis2). Spruces (Pc), subalpine fir (Abies lasiocarpa, Al), black gooseberry (Ribes lacustre [RI]) and several mosses [Ep, Ap] were negatively associated with severity (upper Axis2). Willows [Sa], velvet-leaved blueberry [Vm], Rosa acicularis [Ra], Lonicera involucrata [Li] and Rubus pubescens [Rp] were relatively insensitive to forest age and severity (centre Axis2) (more in Table A-1). Mixed effects models for plant community composition (Table 2ii, Fig. 3) and plot pair comparisons (Fig. 4) reinforced the NMDS results. A severity model with separate $Y R$ intercepts and parallel curves predicted that treated plant communities were $15 \%$ more similar to reference forests at $25 \mathrm{yr}$ than at $10 \mathrm{yr}$ at all levels of $S$. There was a gentle decline in RFSIM from low to medium severity, but a rapid decline at $S>0.8$ in both yr. Reference forests were $65 \%$ similar to one another, thus RFSIM $>60 \%$ on low severity treatments at $25 \mathrm{yr}$, represents nearly full convergence when allowing for experimental error. Community composition converged over the full range of treatments. Crown closure better predicted CONVG than severity (Fig. 3b, Table 2ii), but contrary to $\mathrm{H} 2$, the rate of convergence declined linearly as $\mathrm{CC}$ increased. Of 299 plot-pairs sampled in both yr, $74 \%$ were compositionally more similar at $25 \mathrm{yr}$ than at $10 \mathrm{yr}$, while $26 \%$ diverged (Fig. 4). Among diverging plot pairs, $80 \%$ were $>65 \%$ similar at $10 \mathrm{yr}$, suggesting divergence was mostly due to experimental error (i.e., 
282 randomly relocating subplots). All 4 diverging plot pairs that were $<55 \%$ similar at $10 \mathrm{yr}$ included an anomalous

283 DT plot situated in an aspen clone.

284 Species diversity: 167 taxa (98 native trees, shrubs and herbs, 8 non-native herbs, 61 bryophytes and 285 macrolichens) were recorded in sample quadrats, including 154 in experimental plots, and an additional 12 (1 286 tree, 5 forbs, 3 bryophytes, 3 liverworts) found only in RF. We recorded 98 taxa in plots sampled at $10 \mathrm{yr}$, and 287118 taxa in those same plots at $25 \mathrm{yr}$. Of 30 taxa recorded only at $10 \mathrm{yr}, 73 \%$ were early seral forbs, grasses, 288 and mosses; of 51 taxa recorded only at $25 \mathrm{yr}$, there were 7 shade-loving forbs, 4 bryophytes, and 22 lichens.

Plot scale richness increased across the board from 10 to $25 \mathrm{yr}$. Richness declined linearly with severity at $10 \mathrm{yr}$, but at $25+\mathrm{yr}$, the relationship was cubic, with the most taxa at low and high $S$ and fewest at $0.6<S<0.7$ (RICH, Table 2iii, Fig. 5a). The crown closure model, predicting negative linear relationships with CC in both years, fit almost as well $(\mathrm{AIC}=386$ vs. 385). Species evenness, also decreased linearly with CC, but, unlike richness, it declined with stand age, and the crown closure model fit considerably better than the severity model (EVEN; Fig. 5b, Table 2iii). Richness of epiphytes (EPIRICH) and mycotrophs (MYCRICH) were insensitive to site preparation severity but were higher in reference forests than in 25 yr-old experimental stands (Fig. 5c, d; Table 2iii). Also, there were more epiphytic taxa on open-canopied pines than beneath denser canopies.

Invasive non-native plants: Eurasian hawkweeds of the subgenus Pilosella (Hieracium caespitosum, $H$. piloselloides, $H$. aurantiacum) were pervasive in both yr. Clovers (Trifolium hybridum, T. pratense) were common on burned windrows at $10 \mathrm{yr}$ but not at $25 \mathrm{yr}$. Dandelion (Taraxacum officinale), birds-foot trefoil (Lotus corniculatus), Kentucky bluegrass (Poa pratensis) and Canada thistle (Cirsium arvense) were rare. In reference forests we found one patch of hawkweed $(0.1 \pm 0.1 \%$ cover $)$ and no other non-natives. In the experimental area, hawkweed cover was $10 \%$ at $10 \mathrm{yr}$ and $2 \%$ at $25 \mathrm{yr}$. Total non-native cover was barely higher. The best models (HAWK, NNAT; Table 2iv, Fig. 6a-b) predicted a monotonic increase with severity at $10 \mathrm{yr}$, but a more complex cubic relationship at $25 \mathrm{yr}$ with highest invasive cover at $S=0.3$ and lowest at $0.7<S<0.9$. Although 
PSIZE functions) fit less well than severity models.

There was no evidence of negative correlations between hawkweed abundance and native herb diversity or cover. Correlations were mostly non-significantly positive, but at least one major understory plant (bunchberry, $r=-0.31 ; P=0.006$ ) was significantly negatively associated with hawkweeds. Non-natives other than hawkweeds were 25 times more abundant on burned than unburned plots at $10 \mathrm{yr}$ ( $5 \%$ vs. $0.2 \%$ cover; $\mathrm{K}$ $\left.\mathrm{W}: X^{2}{ }_{1}=3.9, P=0.049\right)$ and $>50$ times more abundant at $25+$ yr $\left(0.08 \%\right.$ vs. $0.0015 \%, \mathrm{~K}-\mathrm{W}: X^{2}{ }_{1}=8.3, P=$ 0.004). Overall, these invasives were 128 times more abundant at $10 \mathrm{yr}$ than at $25+\mathrm{yr}\left(\mathrm{K}-\mathrm{W}: X^{2}{ }_{1}=4.9, P=\right.$ $0.03)$.

Berry-producers: Velvet-leaved blueberry was the dominant berry-producer at Bednesti except on burned windrows where the dominant berry producers were wild strawberry (Fragaria virginiana) and prickly rose (Rosa acicularis). Best-fit models were complex functions showing that berry producers declined with stand age and treatment severity, peaking at $0.2<S<0.5$ at $25 \mathrm{yr}$ (BLUEB, BERRY; Fig. 6c-d, Table 2iv). Tree size and crown closure were poorer predictors than severity.

Lodgepole pine blister rusts and their alternate hosts: Comandra blister rust infection of pine was observed in every surveyed plot (SH, DH, PI, BW) with cumulative infection ranging from 1 to 8 trees per plot at $25 \mathrm{yr}$. False toadflax was recorded on just one 25-yr old SH and three RF subplots. Consequently, we couldn't detect a relationship between false toadflax abundance and rust infection $(P>0.90)$, nor differences in false toadflax abundance between 10 and $25+\mathrm{yr}\left(\mathrm{K}-\mathrm{W} X_{2_{1}}=2.2, P=0.14\right)$. At $25+\mathrm{yr}$, false toadflax was significantly more abundant at low (RF, SH, DT) than medium or high severity (CM, PI, FM, BW; K-W: $\left.X 2_{1}=4.2, P=0.04\right)$. Perversely, the probability of comandra rust infection increased with severity (C-RUST; Table 2iv, Fig. 7): a poisson model with $S$ had significantly better fit than the null model (AIC 91 vs.96, $P=0.009$ ), and slightly better fit than a PSIZE model $(\mathrm{AIC}=94$.

We were unable to fit a model for stalactiform rust because infection ranged from 0 to 2 trees per plot with 13 of 20 plots having no stalactiform rust. But Orobanchaceae hosts were ubiquitous, averaging $0.7 \%$ cover. 
330 Cow-wheat (Melampyrum lineare) was common in both yr; scarlet paintbrush (Castilleja miniata) was mostly on

331 burned windrows at $25 \mathrm{yr}\left(\mathrm{K}-\mathrm{W} X 2_{1}=13.7, P=0.0002\right)$; yellow rattle (Rhinanthus minor) was seen on trails but

332 not recorded in quadrats. The best fits for cow-wheat and total Orobanchaceae cover were high severity

333 threshold models with a significant $Y R \times B W$ interaction (COWWH, OROB; Table 2iv, Fig. 6e-f). On unburned

334 treatments, $O R O B$ dropped from $>2 \%$ at $10 \mathrm{yr}$ to $0.4 \%$ at $25+\mathrm{yr}$. Burned windrows had significantly less

$335 \mathrm{COWWH}$ and $O R O B$ than unburned plots at $10 \mathrm{yr}$, but more $O R O B$ at $25 \mathrm{yr}$ due to an increase in scarlet

336 paintbrush. PSIZE and CC models had a much poorer fit (Table 2iv).

337 Hypotheses: In summary, there was no evidence that plant community composition on treatments of lower vs.

338 higher severity diverged over time, refuting H1 (Figs. 2-4). Tree size and crown closure increased with site

339 preparation severity (Fig 1), but the rate of convergence decreased rather than increased at higher crown

340 closure and severity (Fig 3b), refuting $\mathrm{H} 2$ and lending support to $\mathrm{H} 3$. Eleven of 13 variables had a better fit with

341 a crown closure model than a severity model, further refuting $\mathrm{H} 2$. Closer examination of community composition

342 suggests that $\mathrm{H} 3$ was fully supported at $\mathrm{yr} 10$, but changes after yr 10 supported $\mathrm{H} 3$ on burned windrows only.

343 Specifically, on burned windrows 7 of 15 indicators suggested delayed succession between 10 and 25 yr,

344 whereas 2 suggested accelerated succession; on intermediate treatments (CM, PI, FM), 2-3 indicators each

345 suggested delayed succession, whereas 3-4 indicators suggested accelerated succession.

346 Discussion

347 In the 1980s, management of public forest lands in central BC followed trends in Fennoscandia and the

348 southeastern US by shifting from reliance on natural pine regeneration to intensive site preparation, artificial

349 regeneration and control of competing vegetation to enhance wood yields. The pendulum swung back in

350 following decades to less intensive practices intended to achieve satisfactory reforestation at minimal cost

351 (Hawkins et al. 2006). In the 2010s, most newly logged pine sites are planted with good quality seedlings onto

352 unprepared sites with minimal soil disturbance. Twenty-fifth yr monitoring of successional trajectories and plant

353 indicators at Bednesti can help to evaluate some of the resource management tradeoffs associated with these 
354 shifts in practices and priorities.

355 Successional trajectories: We proposed three hypotheses regarding patterns of forest succession following 356 site preparation treatments that ranged from winter shearing of above-ground vegetation through several 357 intensities of soil mixing to a very severe burn. Hypothesis $\mathrm{H} 1$ posited that this range of disturbances could launch the plant communities onto divergent successional trajectories whereby plant community composition across treatments became less similar over time. The evidence from plant community ordination and convergence analyses refutes $\mathrm{H} 1$. Overwhelmingly, the Bednesti experimental plant communities became more similar to each other and to the composition of nearby reference forests. At 25-yr, their similarity to reference forest composition (50-60\%) was not much less than the $65 \%$ observed among the 5 reference forest plots themselves. Those pine stands were logged at the same time as the experimental area, but restocked naturally, and are excellent controls for what the experimental plant communities would have become with sufficient natural pine regeneration. Following Holling's (1973) definition of ecological resilience, we conclude that the Bednesti plant communities absorbed the full range of experimental disturbances without shifting to an 367 alternative domain of successional attraction, such as an aspen forest. In that sense, the rehabilitation has successfully restored these sub-boreal plant communities. Avoiding soil compaction and stripping of organic layers (Mackenzie et al. 2005) and planting lodgepole pine were two important site-level management practices that helped maintain or restore resilience. A surrounding landscape that had abundant mature lodgepole pine

371 forests prior to the early 2000s was likely also important in allowing dozens of late seral bryophytes, lichens and 372 mycotrophs to colonize the experiment after ten years.

373 Our second hypotheses, $\mathrm{H} 2$, posited that more severe site preparation would accelerate plant community 374 succession relative to less severe treatments by increasing tree growth rates, speeding crown closure and 375 increasing competition for light and other resources, thereby favouring shade- and stress-tolerant late seral 376 plants (Grime 1979) over intolerant, resource-demanding early seral species (cf. Thompson et al. 2013).

377 Conversely, H3 postulated that more severe site preparation would delay successional replacement of early 
378

379

380

381

382

383

384

385

386

387

388

389

390

391

392

393

394

395

396

397

398

399

400

401

seral by late seral plants. Haeussler et al. $(1999,2002)$ showed that low severity site preparation retains a high proportion of residual and budbanking forest plants whereas higher severity site preparation promotes establishment from seeds and spores. $\mathrm{H} 3$ postulated that more severe treatments create a pulse of resource availability that, while not sufficient to derail successional trajectories (as in $\mathrm{H} 1$ ), do allow pioneer species to thrive longer than on lower severity treatments. These alternative scenarios are relevant to managers seeking to balance species and habitat diversity with timber production while discouraging pests and invasive species.

The evidence regarding $\mathrm{H} 2$ and $\mathrm{H} 3$ was mixed. Our data clearly show that succession was slower on higher severity treatments $(\mathrm{H} 3)$ at $10 \mathrm{yr}$. But between 10 and $25 \mathrm{yr}$, there appears to have been a shift toward scenario $\mathrm{H} 2$. The balance of evidence suggests that during this period, successional replacement of early seral species on higher severity plowing and mixing treatments began to equal or surpass that on low severity treatments. At $25 \mathrm{yr}$, only burned windrows still satisfied H3. Despite having larger trees with denser canopies than the less severe treatments, burned windrows retained significant cover of seral species like fire-moss, yarrow, fireweed, strawberry and paintbrush. Neither soil disturbance nor more rapid growth of overstory trees influenced establishment of late seral mycotrophs and epiphytes.

The wide spacing and generally airy open crowns of planted pines at Bednesti evidently did not provide the strong gradient of light competition that rapidly eliminates early seral vegetation during the stem exclusion stage of forest development on more fertile soils (Coomes and Grubb 2000) or at higher planting densities. It is possible that, despite higher crown closure and having subplots centrally located to minimize edge effects, burned windrow plots (10 m x $50 \mathrm{~m}$ ) were successionally delayed because more side light reached their understories than those of other treatment plots $(25 \mathrm{~m} \times 30 \mathrm{~m})$. We think such treatment artefacts were relatively minor and that belowground factors, including differential budbank and seedbank survival and mineral soil exposure for seedling establishment (earlier described by Haeussler et al. 1999, 2002), soil chemical properties (Mackenzie et al. 2005; Boateng et al. 2010) and soil biology (not studied at Bednesti) were more important than aboveground light competition in explaining differences in successional rates.. 
At the nutritionally poor Bednesti site, below-ground interactions are likely to be more important as

403

404

405

406

407

408

409

410

411

412

413

414

415

416

417

418

419

420

421

422

423

424

425

successional drivers (Aerts 1999) than on a mesotrophic ecosystem such as Bednesti's partner site (Inga Lake) where the same silvicultural treatments had substantially different outcomes (Haeussler et al. 2004). Bardgett et al.'s (2005) synthesis of the role of plant-soil feedbacks in succession, complemented by data from central BC (Kranabetter et al 2009; Kranabetter and Mackenzie 2010), provides a possible process-based explanation for the observed plant community dynamics, particularly delayed succession on burned windrows. Typically, forest soil biological communities switch from bacterially-dominated to fungally-dominated during early primary succession. In tandem, the succession of vascular plants involves a progression from short-lived nonmycorrhizal and nitrogen-fixing species that utilize inorganic forms of nitrogen and other nutrients (e.g., clover, sedges), to longer-lived arbuscular-mycorrhizal species that also derive much of their nutrition from inorganic sources (e.g., fireweed). Dominance then shifts to woody ectomycorrhizal (e.g., conifers) and ericoidmycorrhizal (e.g., blueberries) species that acquire nutrients from organic sources, shade-dependent mycotrophic species that derive $\mathrm{C}$ and $\mathrm{N}$ directly from trees or other established plants (Read et al. 2004), and feathermosses that host nitrogen-fixing cyanobacteria (DeLuca et al. 2002).

Kranabetter and Mackenzie (2010) showed that on infertile sites, ectomycorrizal and ericoid-mycorrhizal plants dominate early stages of secondary succession, whereas on richer sites, non-mycorrhizal and arbuscular-mycorrhizal plants persist longer due to sustained availability of inorganic nutrients. We believe that treatment severity at Bednesti altered the proportions and relative competitiveness of these four plant mycorrhizal functional types. Our results suggest that fire may be inherently different from mechanical treatments in ways that influence nutrient acquisition by plants, but our study lacked low and medium severity burns and also lacked an extreme mechanical treatment with comparable bud- and seedbank damage to burned windrows. Boateng et al. (2010) found higher soil pH, CEC and exchangeable $\mathrm{Ca}$ and $\mathrm{K}$ on burned windrows over $20 \mathrm{yr}$, but no long term changes in soil nitrogen or pine foliar nutrients other than boron. No soil biology data are available to explicitly link soil properties to the plant successional trajectories documented 
426 here. Such process-based work could be a fruitful topic for further research.

427 Management indicator species: The shift to less intensive management in central BC in the 2000s, though

428 driven mainly by economics, was also motivated by a desire to protect soils and other forest values such as

429 biodiversity through prescriptions that are "lighter on the land" (Boateng et al. 2012). Our results for indicator 430 plant species can help assess the merits of this approach.

431 The distribution of invasive non-native herbs at Bednesti provides no easy answers for silviculturists

432 seeking to protect biodiversity. There is abundant scientific evidence that severe soil and vegetation

433 disturbance, whether by mechanical means or fire, increases risks of non-native plant invasion (Langor et al.

434 2014). At Bednesti, non-hawkweed invasives were most frequent on burned windrows, but these species were

435 minor and short-lived -as expected of agronomic plants and weeds on nutrient-deficient sites. Hawkweeds, on

436 the other hand, persisted to $25 \mathrm{yr}$ at low to high disturbance. Pilosella hawkweeds are unusually aggressive

437 invaders in poor soils, forming dense mats that competitively exclude other plants (Kloppel et al. 2003). It is

438 believed they can sequester nitrogen in poor soils (Giroday and Baker 2006), possibly through a positive

439 feedback mechanism with soil microbiota. Although we detected no clear negative impact on native herbs, we

440 believe these hawkweeds pose the first persistent threat to the integrity of central BC lodgepole pine forests

441 from non-native plants. More research is needed to clarify how they maintain themselves in infertile forest

442 understories, their effects on plant competitive relationships and soil biogeochemical processes, and whether

443 they will disappear as the feathermoss carpet thickens at 30-40 yr. Planting pine at higher densities and in

444 mixtures with conifers that cast deeper shade may be one strategy to reduce hawkweeds. But this strategy will

445 also reduce abundance and persistence of valued native plants, including berry producers.

446 For berry-producers, results were straightforward: medium to high severity treatments reduced abundance, 447 particularly of velvet-leaved blueberry. We anticipated that losses of ericoid-mycorrhizal blueberries would be 448 offset by increases in raspberry, wild strawberry and prickly rose, but on this infertile ecosystem, increases in 449 early seral berry-producers, mostly on burned windrows, did not offset losses. Low intensity fire is one of the 
450 best ways to stimulate velvet-leaved blueberry resprouting and berry production (Duchesne and Wetzel 2004).

451 Due to piling of fuels, fire severity at Bednesti greatly exceeded the optimal $0.3 \mathrm{~cm}$ depth-of-burn reported by

452 these authors. For berry producers, notably Vaccinium, broadcast burning appears to better distribute burn

453 impacts and exchangeable cations than the current central BC approach of piling and burning logging slash at 454 roadside.

455 One clear tradeoff of a light-on-the-land strategy is that forest soils, soil biota, seedbanks and budbanks are 456 not periodically rejuvenated as under a wildfire regime (Zackrisson et al. 1996). Foresters have wondered 457 whether prevalence of pine stem rusts could likewise be a result of fire suppression and whether greater use of 458 prescribed fire or mechanical site preparation could reduce rust damage in plantations. At one central BC site, 459 comandra rust incidence was $>85 \%$ when false toadflax was present within $1 \mathrm{~m}$ of the tree and decreased to $46045 \%$ when >15 m away (Reich 2011). At Bednesti, false toadflax was found only in older, less-disturbed pine 461 stands, providing tentative support for the view that soil disturbance could reduce this host in the early years 462 when pines are most liable to infection. Contrary to these findings and an earlier analysis by Reich et al. (2015), 463 our C-RUST model predicted increased infection on more severe treatments.

464 We also found no clear relationship between Orobanchaceae abundance and stalactiform rust infection. 465 While Orobanchaceae hosts were present in every Bednesti plot at 10 and $25 \mathrm{yr}$, stalactiform rust was rarely 466 present. Given co-occurrence of the two stem rusts, the diverse niches of their various hosts, and lack of clarity 467 on how the susceptibility of pine varies with environmental factors that influence abundance of the alternate 468 host, it isn't possible to conclude whether more or less site preparation would reduce rust damage. Much larger 469 treatment units and detailed pre- and post-treatment monitoring are needed to disentangle the complex 470 relationships among the physical and biotic factors that influence infection rates.

\section{Conclusions}

472 Management of lodgepole pine ecosystems for resilient forests that provide a long term supply of timber 473 while sustaining biodiversity, wildlife habitat and other non-timber values involves tradeoffs between creating 
474 and prolonging open early seral habitats with a rich variety of plants and speeding up the development of

475 closed forest habitats to support species at risk from the loss of mature and old growth forests. For BC

476 lodgepole pine ecosystems, such tradeoffs have been accentuated by the 2000 s mountain pine beetle

477 epidemic because 20-40-yr-old plantations are now the dominant category of closed pine forest. Aside from

478 unexpectedly strong persistence of non-native hawkweeds, our study found the plant communities of nutrient-

479 limited lodgepole pine ecosystems to be resilient to a broad spectrum of silvicultural site preparation. The 480 appearance of 51 new species, mainly bryophytes and lichens, 10-25 yr after disturbance suggests, however,

481 that nearby mature pine forests played a role in this resilience that cannot be taken for granted in the aftermath 482 of the beetle.

483 Severe treatments enhanced growth of lodgepole pine, but there was minimal evidence that they 484 accelerated the development of plant communities. Succession was actually delayed on higher severity 485 treatments over the first decade, but by 25 yr only the most extreme treatment (windrowed and burned slash) 486 was still delayed. Less severe broadcast burning will likely provide many benefits of fire while avoiding extreme 487 impacts such as the loss of blueberries. We now disagree with our 10-yr recommendation (Haeussler et al. 488 2002) that medium severity treatments are a good way to balance benefits and risks of site preparation.

489 Instead, 25-yr results suggest managers should address tradeoffs by adopting a diversity of low, medium and 490 high severity practices within stands and across landscapes. Since 1988, the Bednesti study has provided 491 insights into the complexity of practicing ecosystem-specific silviculture that balances benefits and risks for 492 plants and other forest values. Long term maintenance and monitoring of experiments like Bednesti are needed 493 to allow forest management to adapt to ever-changing conditions and concerns.

\section{Acknowledgements}

495 A. Coates, R. Reich, H. Kope, J. Heinemann, P. Ott and M.C. Tsoi assisted with data and reviews of an early 496 draft. Comments from two anonymous reviewers greatly improved the final version. R.G. McMinn, C. von Hahn, 497 D. Bryce, B. Rynsyvin and M. Grismer established and maintained the Bednesti site with funding from the 
498 Government of Canada and the Province of BC. This research was funded by the Resource Practices Branch, 499 BC Ministry of Forests, Lands and Natural Resource Operations. 


\section{References}

Aerts, R. 1999. Interspecific competition in natural plant communities: mechanisms, tradeoffs and plant-soil feedbacks. J. Exp. Bot. 50(330): 29-37. doi.org/10.1093/jxb/50.330.29.

Bardgett, R. D., Bowman, W. D., Kaufmann R., and Schmidt, S. K. 2005. A temporal approach to linking aboveground and belowground ecology. Trends in Ecology and Evolution 20(11): 634-631. doi:10.1016/j.tree.2005.08.005.

Bates, D., Maechler, M., Bolker, B., and Walker, S. 2015. Fitting linear mixed-effects models using Ime4. J. Stat. Softw. 67(1): 1-48. doi:10.18637/jss.v067.i01.

Bedford, L., and Sutton, R. F. 2000. Site preparation for establishing lodgepole pine in the sub-boreal spruce zone of interior British Columbia: the Bednesti trial, 10-year results. For. Ecol. Manage. 126(2): 227-238. dx.doi.org/10.1016/S0378-1127(99)00090-0.

Boateng, J. O., Heineman, J. L., Bedford, L., and Linnell Nemec, A. F. 2010. Twenty-year effects of mechanical site preparation and windrow burning treatments on soil properties and Pinus contora var. latifolia nutrition in subboreal British Columbia. Scand. J. For. Res. 25(6): 515-533. dx.doi.org/10.1080/02827581.2010.519344.

Boateng, J. O., Heineman, J. L., Bedford, L., Linnell Nemec, A. F., McClarnon, J., and Powelson, R. A. 2012. Twenty year site preparation effects on sub-boreal lodgepole pine performance. New Forests 43(4): 457-472. doi:10.1007/s11056-011-9292-6.

Burton, P. J. 2010. Striving for sustainability and resilience in the face of unprecedented change: the case of the mountain pine beetle outbreak in British Columbia. Sustainability 2(8): 2403-2423; doi:10.3390/su2082403.

Cichowski, D., and Williston, P. 2005. Mountain pine beetles and emerging issues in the management of woodland caribou in Westcentral British Columbia. Rangifer Special Issue No. 16: 97-103. dx.doi.org/10.7557/2.25.4.1775.

Coomes, D. A., and Grubb, P. J. 2000. Impacts of root competition in forests and woodlands: a theoretical framework and review of experiments. Ecol. Monogr. 70(2): 171-207. doi:10.1890/0012- 
9615(2000)070[0171:IORCIF]2.0.CO;2. Delong, C., and Tanner, D. 1996. Managing the pattern of forest harvest: lessons from wildfire. Biodiversity \& Conservation 5: 1191-1205. doi:10.1007/BF00051571.

Delong, C., Tanner, D., and Jull, M. J. 1993. A field guide for site identification and interpretation for the southwest portion of the Prince George Forest Region. B.C. Min. For. Land Manage. Handb. No. 16. Available from: https://www.for.gov.bc.ca/hfd/pubs/docs/Lmh/Lmh24.htm [accessed 26 February 2017].

DeLuca, T. H., Zackrisson, O., Nilsson, M.-C., and Sellstedt, A. 2002. Quantifying nitrogen-fixation in feather moss carpets of boreal forests. Nature 419: 917-920. doi:10.1038/nature01051.

Duchesne, L. C., and Wetzel, S. 2004. Effect of fire intensity and depth of burn on lowbush blueberry, Vaccinium angustifolium, and velvet leaf blueberry, Vaccinium myrtilloides, production in eastern Ontario. Can. Field Naturalist 118(2): 195-200. dx.doi.org/10.22621/cfn.v118i2.913.

Ghoussoub, M. 2017. B.C. surpasses worst wildfire season on record -and threat is far from over. CBC News. Posted 16 August 2017. Available from: http://www.cbc.ca/news/canada/british-columbia/b-c-surpasses-worstwildfire-season-on-record-and-threat-is-far-from-over-1.4249435 [accessed 18 August 2017].

Giroday, H. and Baker, V. 2006. Invasive hawkweeds (Hieracium spp.) in northeastern British Columbia. BC Ministry of Forests and Range, Range Branch, Invasive Plants Program, Prince George, BC. 17 p. Available from:

https://www.for.gov.bc.ca/hra/plants/publications/HawkweeedRiskAssessmentforNortheastBC_FINAL_24Oct06.p df [accessed 16 August 2017].

Grime, J. P. 1979. Plant strategies and vegetation processes. John Wiley \& Sons, Chistester, UK. 222 p.

Haeussler, S., Bedford, L., Boateng, J. O., and MacKinnon, A. 1999. Plant community responses to mechanical site preparation in northern interior British Columbia. Can. J. For. Res. 29(7): 1084-1100. doi:10.1139/x99-057.

Haeussler, S., Bedford, L., Leduc, A., Bergeron, Y., and Kranabetter, J. M. 2002. Silvicultural disturbance severity and plant communities of the southern Canadian boreal forest. Silva Fenn. 36(1): 307-327. doi.org/10.14214/sf.565. 
Haeussler, S., Bartemucci, P., and Bedford, L. 2004. Succession and resilience in boreal mixedwood plant communities 15-16 years after silvicultural site preparation. For. Ecol. Manage. 199(2): 349-370. dx.doi.org/10.1016/j.foreco.2004.05.052.

Haeussler, S., Bergeron, Y., Brais, S., and Harvey, B. D. 2007. Natural dynamics-based silviculture for maintaining plant biodiversity in Populus tremuloides-dominated boreal forests of eastern Canada. Botany 85(12): 1158-1170. doi:10.1139/B07-108.

Hawkins, C. B. D., Steele, T. W., and Letchford, T. 2006. The economics of site preparation and the impacts of current forest policy: evidence from central British Columbia. Can. J. For. Res. 36(2): 482-494. 10.1139/x05-262.

Holling, C. S. 1973. Resilience and stability of ecological systems. Annu. Rev. Ecol. Syst. 4: 1-23. doi:10.1146/annurev.es.04.110173.000245.

Kloppel, M., Smith, L. and Syrett, P. 2003. Predicting the impact of the biocontrol agent Aulacidea subterminalis (Cynipidae) on growth of Hieracium pilosella (Asteraceae) under differing environmental conditions in New Zealand. Biocontrol Science and Technology 13: 207-218.

Kranabetter, J. M., and Mackenzie, W. H. 2010. Contrasts among mycorrhizal guilds in foliar nitrogen concentration and $\delta^{15} \mathrm{~N}$ along productivity gradients of a boreal forest. Ecosystems 13: 108-117. doi:10.1007/s10021-009-9304y.

Kranabetter, J. M., Durall, D. M., and Mackenzie, W. H. 2009. Diversity and species distribution of ecomycorrhizal fungi along productivity gradients of a southern boreal forest. Mycorrhiza 19(2): 99-1111. doi:10.1007/s00572008-0208-z.

Langor, D., Cameron, E. K., MacQuarrie, C. J. K., McBeath, A., McClay, A., Peter, B., Pybus, M., Ramsfield, T., Ryall, K., Scarr, T., Yemshanov, D., DeMarchant, I., Foottit, R., and Pohl, G. R. 2014. Non-native species in Canada's boreal zone: diversity, impacts and risk. Environ. Rev. 22(4): 372-420. doi:10.1139/er-2013-0083. Mackenzie, M. D., Schmidt, M. G., and Bedford, L. 2005. Soil microclimate and nitrogen availability 10 years after mechanical site preparation in northern British Columbia. Can. J. For. Res. 35: 1854-1866. doi:10.1139/x05-127. 
Massicotte, H. B., Peterson, R. L., Melville, L. H., and Luoma, D. L. 2012. Biology of mycoheterotrophic and mixotrophic plants. Chap. 5 in The Biocomplexity of Plant-Fungal Interactions. Edited by D. Southworth. Wiley Blackwell, West Sussex, UK. pp. 109-130. doi:10.1002/9781118314364.ch5.

Oksanen, J., Blanchet, F. G., Friendly, M., Kindt, R., Legendre, P., McGlinn, D., Minchin, P. R., O'Hara, R. B., Simpson, G. L., Solymos, P. M., Stevens, H.M., Szoecs, E., and Wagner, H. 2017. 'vegan': Community Ecology Package in R. January 1, 2017 edition. Available from: https://cran.r-project.org/web/packages/vegan/vegan.pdf [accessed 26 February 2017].

Pinheiro, J. Bates, D., DebRoy, S., Sarkar, D., and R Core Team. 2015. 'nlme': Linear and Nonlinear Mixed Effects Models. R package version 3.1-120. Available from: http://CRAN.R-project.org/package=nlme [accessed 25 March 2015].

R Core Team. 2017. R: A language and environment for statistical computing. R Foundation for Statistical Computing, Vienna, Austria. Available from: http://www.R-project.org/ [accessed18 August 2017].

Read, D. J., Leake, J. R., and Perez-Moreno, J. 2004. Mycorrhizal fungi as drivers of ecosystem processes in heathland and boreal forest biomes. Can. J. Bot. 82(8): 1243-1263. doi:10.1139/b04-123.

Reich, R. 2011. Comandra blister rust resistance, a needle in the haystack? In Proceedings of the 58th annual Western International Forest Disease Work Conference, Valemount, BC, 4-8 October, 2010. Compiled by M. Fairweather. US For. Serv. AZ Zone Forest Health, Flagstaff, AZ. pp. 105-111. Available from: https://www.fs.fed.us/foresthealth/technology/wif/proceedings/WIFDWC2010.pdf [accessed 26 February, 2017].

Reich, R.W., Heineman, J. L., Linnell Nemec, A. F., Bedford, L., Boateng, J. O., and Kaffanke, T. 2015. Hard pine stem rusts on lodgepole pine at a site preparation study in sub-boreal British Columbia: effects over 24 years. Can. J. For. Res. 45(4): 411-421. doi:10.1139/cjfr-2014-0388.

Roberts, M. R. 2007. A conceptual model to characterize disturbance severity in forest harvests. For. Ecol. Manage. 242(1): 58-64. doi: 10.1016/j.foreco.2007.01.043. 
Shore, T. L., Brooks, J. E., and Stone, J. E. (Editors). 2004. Mountain Pine Beetle Symposium: Challenges and Solutions Conference Proceedings, 30-31 October, 2003, Kelowna, BC. NRC Can. For. Serv. Pac. For. Centre Inf. Rep. BC-X-399. Available from: http://www.cfs.nrcan.gc.ca/pubwarehouse/pdfs/25159.pdf\#page=47 [accessed 26 February, 2015].

Soil Classification Working Group. 1998. The Canadian system of soil classification. $3^{\text {rd }}$ Ed., Agriculture and AgriFood Canada, Ottawa, ON. 187 p.

Thompson, I. D., Kirk, D. A., and Jastrebski, C. 2013. Does postharvest silviculture improve convergence of avian communities in managed and old-growth boreal forest? Can. J. For. Res. 43: 1050-1062.

Wang, T., Hamann, A., Spittlehouse, D. L. and Murdock, T. 2012. ClimateWNA - high resolution spatial climate data for Western North America. Journal of Applied Meteorology and Climatology 51: 16-29. doi:10.1175/JAMCD-11-043.1

Wilson, L. M. 2006. Key to Identification of Invasive and Native Hawkweeds (Hieracium spp.) in the Pacific Northwest. BC Min. For. Range, For. Pract. Br., Kamloops, BC. Available from: https://www.for.gov.bc.ca/hfp/publications/00230/Hawkweed\%20key_PNW_R3-June06.pdf [accessed 26 February, 2015].

Woods, A. J., Coates, K. D., Watts, M., Foord, V. and Holtzmann, E. I. 2017. Warning signals of adverse interactions between climate change and native stressors in British Columbia forests. Forests 8(8), 280; doi:10.3390/f8080280.

Zackrisson, O., Nilsson, M.-C., and Wardle, D. A. 1996. Key ecological function of charcoal from wildfire in the boreal forest. Oikos 77(1): 10-19. doi:10.2307/3545580. 


\section{Tables}

Table 1. Description of explanatory and response variables.

\begin{tabular}{|c|c|c|c|}
\hline \multicolumn{4}{|c|}{ (a) Explanatory variables } \\
\hline Abbreviation & Description & Units & Range of Values \\
\hline$S$ & Site preparation severity. Equation (1) in text & none & 0 to 1 \\
\hline$B W$ & Dummy variable for burned windrow & none & $0=$ unburned; $1=$ burned \\
\hline$R F$ & Dummy variable for reference forest & none & $\begin{array}{l}0=\text { experimental plot; } 1= \\
\text { reference forest }\end{array}$ \\
\hline$Y R$ & Year of sampling & years & $1997=0 ; 2012=15$ \\
\hline AGE & Age of lodgepole pine stand & years & $10-46$ \\
\hline PSIZE & $\begin{array}{l}\text { Size of lodgepole pine from Axis1 of PCA of height, diameter, } \\
\text { basal area, stem volume and crown volume index. }\end{array}$ & none & $0-1.6$ \\
\hline CC & $\begin{array}{l}\text { Tree crown closure = ocular estimate of cover of lodgepole pine } \\
\text { and other canopy trees of equal or greater height }\end{array}$ & $\%$ & $16-80$ \\
\hline NORTH & North:South geographic coordinate of plot & none & $0-8$ \\
\hline EAST & East:West geographic coordinate of plot & none & $0-8$ \\
\hline$T O A D$ & Mean cover of Geocaulon lividum in plot (C-RUST only) & $\%$ & $0-0.03$ \\
\hline COWWH & Mean cover of Melampyrum lineare in plot (S-RUST only) & $\%$ & $0-5.8$ \\
\hline$O R O B$ & $\begin{array}{l}\text { Mean cover of Orobanchaceae (Melampyrum + Castilleja) in } \\
\text { plot (S-RUST only) }\end{array}$ & $\%$ & $0-5.8$ \\
\hline \multicolumn{4}{|c|}{ (b) Response variables } \\
\hline Abbreviation & Description & $\mathrm{n}$ & Treatments and Years \\
\hline \multicolumn{4}{|c|}{ i. Tree Size and Crown Closure } \\
\hline PSIZE & Size of lodgepole pine (see above). & 60 & all \\
\hline CC & Tree crown closure (see above) & 60 & all \\
\hline
\end{tabular}




\begin{tabular}{|c|c|c|c|}
\hline \multicolumn{4}{|c|}{ ii. Plant Community Composition } \\
\hline RFSIM & $\begin{array}{l}\text { Mean similarity }(1-B C D)^{*} \text { of each plot at } 10 \mathrm{yr} \text { and } 25 \text { to the } 5 \\
\text { (or } 4 \text { other) RF plots }\end{array}$ & 60 & $\begin{array}{l}\text { SH, DT, CM, FM, BW at } 10 \\
\text { and } 25 \mathrm{yr} ; \mathrm{PI} \text { and RF at } 25 \mathrm{yr} \\
\text { only }\end{array}$ \\
\hline CONVG & $\begin{array}{l}\text { Mean change in similarity }\left[(1-B C D)_{25}-(1-B C D)_{10}\right] \text { for each plot } \\
\text { relative to all other plots (positive = converging; negative = } \\
\text { diverging) }\end{array}$ & 25 & SH, DT, CM, FM, BW \\
\hline \multicolumn{4}{|c|}{ iii. Species Diversity } \\
\hline $\mathrm{RICH}$ & Species richness, subplot data pooled at plot scale & 60 & All \\
\hline EVEN & Pielou's species evenness index, plot scale data & 60 & All \\
\hline EPIRICH & Richness of epiphytes on lodgepole pine, 5 trees per plot & 35 & 7 treatments at $25+y r$ \\
\hline $\mathrm{MYCRICH}$ & Richness of mycoheterotrophs and mixotrophs, plot scale data & 35 & 7 treatments at $25+y r$ \\
\hline \multicolumn{4}{|c|}{ iv. Abundance of Management Indicator Species } \\
\hline HAWK & Mean cover of Pilosella hawkweeds in plot & 60 & All \\
\hline NNAT & Mean cover of all non-native plants in plot & 60 & All \\
\hline BLUEB & Mean cover of Vaccinium myrtilloides in plot & 60 & All \\
\hline BERRY & Mean cover of all berry-producing plants in plot & 60 & All \\
\hline TOAD & Mean cover of Geocaulon lividum in plot & 60 & All \\
\hline COWWH & Mean cover of Melampyrum lineare in plot & 60 & All \\
\hline OROB & Mean cover of Melampyrum + Castilleja in plot & 60 & All \\
\hline C-RUST & $\begin{array}{l}\text { Cumulative number of trees infected with comandra blister rust } \\
\text { in plot from } 1994 \text { to } 2012\end{array}$ & 20 & SH, DT, CM, BW \\
\hline S-RUST & $\begin{array}{l}\text { Cumulative number of trees infected with stalactiform blister } \\
\text { rust in plot from } 1994 \text { to } 2012\end{array}$ & 20 & SH, DT, CM, BW \\
\hline
\end{tabular}

${ }^{*} \mathrm{BCD}$ is the Bray-Curtis distance metric 
Table 2. Comparison of best-fitting disturbance severity and tree size/crown closure models for each response variable, with best overall model indicated by bold Akaike information criterion (AIC).

\begin{tabular}{|c|c|c|c|c|c|}
\hline \multirow{2}{*}{$\begin{array}{l}\text { Response } \\
\text { Variable* }^{*}\end{array}$} & \multirow{2}{*}{ Powert } & \multicolumn{2}{|l|}{ Severity Model } & \multicolumn{2}{|c|}{ Tree Size/Crown Closure Mode } \\
\hline & & Equation & AIC & Equation & AIC \\
\hline \multicolumn{6}{|c|}{ i. $\quad$ Tree Size and Crown Closure } \\
\hline PSIZE & 1 & $\begin{array}{l}Y=\left(-0.67+0.1 \times A G E-0.0012 \times A G E^{2}\right)-(1.34+ \\
0.0045 x Y R) \times S+(3.44+0.0099 x Y R) \times S^{2}-(2.09- \\
0.01 \times Y R) \times S^{3}\end{array}$ & -80 & $\mathrm{n} / \mathrm{a}$ & \\
\hline CC & 1 & $\begin{array}{l}Y=(26.4+20.8 \times R F)-(94.8-15 \times Y R) \times S+(371- \\
36.8 \times Y R) \times S^{2}-(249-23 \times Y R) \times S^{3}\end{array}$ & 439 & $n / a$ & \\
\hline \multicolumn{6}{|c|}{ ii. Plant Community Composition } \\
\hline RFSIM & 1 & $\begin{array}{l}Y=(0.51+0.0096 \times Y R)-0.38 \times S+0.80 \times S^{2}- \\
0.38 \times S^{3}\end{array}$ & -200 & $\begin{array}{l}Y=(0.48+0.021) \times Y R-(0.001 \\
-0.0002 \times Y R) \times C C\end{array}$ & -190 \\
\hline CONVG & 1 & $Y=0.067-0.056 x S$ & -116 & $Y=0.08-0.001 \times C C_{10}$ & -120 \\
\hline \multicolumn{6}{|c|}{ Species Diversity: } \\
\hline $\mathrm{RICH}$ & 1 & $\begin{array}{l}Y=(39.7+0.43 \times Y R)-(11.9+1.01 \times Y R) \times S- \\
(4.46 x Y R) \times S^{2}+(4.18 x Y R) \times S^{3}\end{array}$ & 385 & $\begin{array}{l}Y=(41.9+0.82 \times Y R)- \\
0.22 \times C C\end{array}$ & 386 \\
\hline EVEN & 1 & $\begin{array}{l}Y=(0.75-0.0086 x Y R)+0.28 x S-1.13 \times S^{2}+ \\
0.74 x S^{3}\end{array}$ & -147 & $\begin{array}{l}Y=0.82-(0.0035+ \\
0.000086 \times Y R) \times C C\end{array}$ & -159 \\
\hline EPIRICH & 1 & $Y=12.7+7.1 \times R F$ & 149 & $Y=21.5-0.13 \times C C$ & 177 \\
\hline $\mathrm{MYCRICH}$ & 1 & $Y=3.5+2.5 x R F$ & 133 & $Y=0.26+2.96 \times P S I Z E$ & 139 \\
\hline \multicolumn{6}{|c|}{ iv. Abundance of Management Indicator Species } \\
\hline HAWK & $1 / 3$ & $\begin{array}{l}Y=(2.27-0.14 Y R)+(0.67+0.56 Y R) \times S- \\
(1.23 Y R) \times S^{2}+(0.69 Y R) \times S^{3}\end{array}$ & 92 & $\begin{array}{l}Y=2.41-2.41 \times P S I Z E- \\
4.97 \times P S I Z E^{2}+1.70 \times P S I Z E^{3}\end{array}$ & 99 \\
\hline NNAT & $1 / 3$ & $\begin{array}{l}Y=(2.22-0.13 x Y R)+(0.81+0.55 x Y R) \times S- \\
(1.23 x Y R) \times S^{2}+(0.69 x Y R) \times S^{3}\end{array}$ & 92 & $\begin{array}{l}Y=Y=244-2.49 x P S I Z E- \\
5.17 x P S I Z E^{2}+1.78 x P S I Z E^{3}\end{array}$ & 98 \\
\hline$B L U E B$ & 0.5 & $\begin{array}{l}Y=(12.7-0.71 \times Y R)-(49.8-3.87 x Y R) \times S+(86.2- \\
6.63 \times Y R) \times S^{2}-(47.8-3.43 \times Y R) \times S^{3}\end{array}$ & 165 & $Y=5.24-0.048 x C C$ & 187 \\
\hline
\end{tabular}




\begin{tabular}{|c|c|c|c|c|c|}
\hline BERRY & 0.5 & $\begin{array}{l}Y=(6.54-0.21 x Y R)+(2.69-0.83 x Y R) \times S- \\
(1.4 x Y R) \times S^{2}+(0.78 x Y R) \times S^{3}\end{array}$ & 177 & $Y=5.1-0.99 x P S I Z E$ & 183 \\
\hline COWWH & 0.25 & $Y=(1.1-0.032 \times Y R)-(0.59-0.036 \times Y R) \times B W$ & 23 & $\begin{array}{l}Y=(1.17-0.021 \times Y R)- \\
0.0039 \times C C\end{array}$ & 37 \\
\hline$O R O B$ & 0.3 & $Y=1.18-0.04 x Y R-(0.69 x B W-0.07 x Y R) \times B W$ & 45 & $\begin{array}{l}Y=1.22-1.08 x P S I Z E+ \\
0.50 x P S I Z E^{2}\end{array}$ & 66 \\
\hline$C-R U S T$ & 1 & $Y=2.29 e^{0.99 S}$ & 91 & $Y=1.18 \mathrm{e}^{1.13 \times P S I Z E}$ & 94 \\
\hline$S-R U S T$ & & low rates of stalactiform blister rust ir & 1010 & pine & \\
\hline
\end{tabular}

*defined in Table $1 \mathrm{~b}$.

†Value of the exponent in a normalizing power transformation of the dependent variable $(1=$ untransformed). Parameter estimates are for the transformed variable (also see $Y$ axes in Figs. 3, 5-6). 
Table 3. Results of a non-metric multi-dimensional scaling (NMDS) ordination of vegetation cover by species at Bednesti at $10 \mathrm{yr}$ ( 5 treatments, 25 plots) and $25+\mathrm{yr}$ ( 7 treatments, 35 plots) with explanatory variables (defined in Table 1a) ranked by the strength of their fit $\left(r^{2}\right)$ with the overall NMDS solution.

\begin{tabular}{|c|c|c|c|c|c|}
\hline \multicolumn{6}{|c|}{ (a) NMDS Ordination Properties } \\
\hline \multicolumn{2}{|c|}{\begin{tabular}{l|l} 
Input & 1 \\
&
\end{tabular}} & Number & \multicolumn{2}{|c|}{ Output } & Value \\
\hline \multicolumn{2}{|l|}{ Plots } & 60 & \multicolumn{2}{|c|}{ Dimensions } & 3 \\
\hline \multirow[t]{2}{*}{ Species } & \multicolumn{2}{|c|}{134} & \multicolumn{2}{|l|}{ Stress } & 0.1367623 \\
\hline & & & \multicolumn{2}{|c|}{ Shepard plot non-metric fit: } & $R^{2}=0.981$ \\
\hline \multicolumn{6}{|c|}{ (b) Correlations of Explanatory Variables with the NMDS Ordination } \\
\hline \multirow[b]{2}{*}{ Variable } & \multirow[b]{2}{*}{$r^{2}$} & \multirow{2}{*}{$\begin{array}{l}\text { Monte Carlo } \\
P \text {-value }\end{array}$} & \multicolumn{3}{|c|}{ Correlation Coefficients (r) with NMDS Axes* } \\
\hline & & & Axis1 & Axis2 & Axis3 \\
\hline PSIZE & 0.927 & 0.001 & 0.906 & -0.411 & 0.100 \\
\hline$A G E$ & 0.886 & 0.001 & 0.997 & -0.018 & 0.080 \\
\hline$Y R$ & 0.880 & 0.001 & 0.942 & -0.239 & 0.236 \\
\hline$S$ & 0.659 & 0.001 & -0.326 & -0.924 & 0.201 \\
\hline$C C$ & 0.541 & 0.001 & -0.320 & -0.944 & 0.085 \\
\hline NORTH & 0.122 & 0.07 & -- & -- & -- \\
\hline EAST & 0.043 & 0.46 & -- & -- & -- \\
\hline
\end{tabular}

*For variables with $P<0.05$, r-values are shown for each axis (strongest correlations highlighted). 
Appendix Table A-I. Plant species codes from Figure $1 \mathrm{~b}$ with scientific and common names and seral stage classification.

\begin{tabular}{|c|c|c|c|}
\hline Codes & Scientific Name & Common Name & Seral stage $^{\dagger}$ \\
\hline \multicolumn{4}{|c|}{ Trees and Shrubs } \\
\hline $\mathrm{Al}$ & Abies lasiocarpa & subalpine fir & late \\
\hline Pc & Picea spp. & interior spruce and black spruce & generalist \\
\hline $\mathrm{Pn}$ & Pinus contorta var. contorta & lodgepole pine & generalist (e) \\
\hline $\mathrm{Pt}$ & Populus tremuloides & trembling aspen & generalist (e) \\
\hline$A v$ & Alnus viridis ssp. crispa & green alder & generalist \\
\hline$\overline{\mathrm{Li}}$ & Lonicera involucrata & black twinberry & generalist \\
\hline $\mathrm{RI}$ & Ribes lacustre & black gooseberry & generalist (I) \\
\hline $\mathrm{Ra}$ & Rosa acicularis & prickly rose & generalist \\
\hline $\mathrm{Ri}$ & Rubus idaeus & red raspberry & early \\
\hline $\mathrm{Sa}$ & Salix spp. & willows & generalist (e) \\
\hline $\mathrm{Sb}$ & Spiraea betulifolia & white meadow-sweet & generalist \\
\hline Vm & Vaccinium myrtilloides & velvet-leaved blueberry & generalist \\
\hline \multicolumn{4}{|c|}{ Native forbs and dwarf shrubs } \\
\hline Ac & Achillea millefolium & yarrow & early \\
\hline An & Anaphalis margaritacea & pearly everlasting & early \\
\hline $\mathrm{Cm}$ & Chimaphila menziesii & Menzies' pipsissewa & late \\
\hline Co & Cornus canadensis & bunchberry & generalist \\
\hline Ea & Epilobium angustifolium & fireweed & generalist (e) \\
\hline Ec & Epilobium ciliatum & purple-leaved willowherb & early \\
\hline Fv & Fragaria virginiana & wild strawberry & early (g) \\
\hline $\mathrm{Ga}$ & Gentianella amarella & northern gentian & early \\
\hline $\mathrm{Gr}$ & Goodyera repens & dwarf rattlesnake orchid & late \\
\hline $\mathrm{Ha}$ & Hieracium albiflorum & white hawkweed & early \\
\hline $\mathrm{Lb}$ & Linnaea borealis & twinflower & generalist \\
\hline La & Lycopodium annotinum & stiff club-moss & late \\
\hline Ld & Lycopodium dendroidium & ground-pine & late \\
\hline $\mathrm{Ml}$ & Melampyrum lineare & cow-wheat & generalist \\
\hline Os & Orthilia secunda & one-sided wintergreen & late \\
\hline Vc & Vaccinium caespitosum & dwarf blueberry & generalist \\
\hline
\end{tabular}




\begin{tabular}{|c|c|c|c|}
\hline Vi & Viola spp. & violets & generalists \\
\hline \multicolumn{4}{|c|}{ Native graminoids } \\
\hline As & Agrostis scabra & hair bentgrass & early \\
\hline Cc & Calamagrostis canadensis & bluejoint reedgrass & generalist \\
\hline $\mathrm{Cr}$ & Calamagrostis rubescens & pinegrass & generalist \\
\hline Cx & Carex spp. & sedges & early \\
\hline Fo & Festuca occidentalis & western fescue & generalist \\
\hline $\mathrm{Ja}$ & Juncus arcticus & arctic rush & early \\
\hline Je & Juncus ensifolius & dagger-leaf rush & early \\
\hline Po & Poaceae & miscellaneous native grasses & generalists (e) \\
\hline \multicolumn{4}{|c|}{ Non-native herbs } \\
\hline Cs & Cirsium arvense & Canada thistle & early \\
\hline LC & Lotus corniculatus & birdsfoot trefoil & early \\
\hline $\mathrm{Hp}$ & $\begin{array}{l}\text { Hieracium spp. (Pilosella } \\
\text { subgenus) }\end{array}$ & Pilosella hawkweeds & early \\
\hline To & Taraxacum officinale & dandelion & early \\
\hline $\mathrm{Tr}$ & Trifolium spp. & clovers & early \\
\hline \multicolumn{4}{|c|}{ Bryophytes } \\
\hline Ap & Aulacomium palustre & glow moss & generalist \\
\hline $\mathrm{Bh}$ & Barbilophozia hatcheri & Hatcher's leafy liverwort & late \\
\hline $\mathrm{Bl}$ & Barbilophozia lycopodioides & common leafy liverwort & late \\
\hline By & Bryum spp. & thread-mosses & early \\
\hline $\mathrm{Br}$ & Brachythecium spp. & ragged mosses & generalists (e) \\
\hline Cp & Ceratodon purpureus & fire-moss & early \\
\hline $\mathrm{Di}$ & $\begin{array}{l}\text { Dicranum spp. (other than } D \text {. } \\
\text { polysetum) }\end{array}$ & heron's-bill moss & late \\
\hline $\mathrm{Dp}$ & Dicranum polysetum & wavy-leaved moss & generalist \\
\hline Ep & Eurhynchium pulchellum & elegant beaked-moss & generalist (I) \\
\hline Hs & Hylocomium splendens & step moss & late \\
\hline Lo & Lophozia spp. & leafy liverworts & late \\
\hline $\mathrm{PI}$ & Pleurozium schreberi & red-stemmed feathermoss & generalist \\
\hline $\mathrm{Ph}$ & Pohlia spp. & pohlia mosses & early $(\mathrm{g})$ \\
\hline
\end{tabular}




\begin{tabular}{|c|c|c|c|}
\hline $\mathrm{Pj}$ & Polytrichum juniperinum & juniper haircap moss & early \\
\hline $\mathrm{Pt}$ & Ptilium crista-castrensis & knight's plume feather moss & late $(g)$ \\
\hline $\mathrm{Pp}$ & Ptilidium pulcherrimum & western naugahyde liverwort & generalist \\
\hline \multicolumn{4}{|c|}{ Lichens } \\
\hline $\mathrm{Ce}$ & Cetraria islandica & Icelandmoss & generalist \\
\hline $\mathrm{Hy}$ & Hypogymnia spp. & bone lichens & epiphyte \\
\hline Lp & Pezizomycotina lichens & miscellaneous lichens & epiphytes \\
\hline $\mathrm{Py}$ & Parmeliopsis hyperopta & grey starburst & epiphyte \\
\hline Ps & Parmelia sulcata & hammered crottle lichen & epiphyte \\
\hline $\mathrm{Pe}$ & Peltigera aphthosa & silver-edge pelt lichen & generalist \\
\hline $\mathrm{Pg}$ & Platismatia glauca & ragbag lichen & epiphyte \\
\hline $\mathrm{Rm}$ & Ramalina spp. & ribbon lichens & epiphyte \\
\hline
\end{tabular}

$\dagger(\mathrm{e}),(\mathrm{g})$ or (I) indicates that listed seral stage is transitional to early, generalist or late, respectively. Epiphytes may be generalists or late seral but require tree substrate and generally increase with age.

Note: Nomenclature throughout manuscript follows Klinkenberg (2017). 167 taxa were recorded (to the species or subgenus level). The NMDS included 134 taxa because epiphytes recorded only on sample pines at 25+yr were excluded (no matching $10 \mathrm{yr}$ data) and some infrequent or difficult taxa were lumped by genus or family. For display purposes, Fig. 1b and Table 1-A show 66 common or influential taxa and some related species with similar NMDS coordinates were lumped (e.g., Lp).

\section{Reference}

Klinkenberg, B. (Editor) 2017. E-Flora BC: Electronic Atlas of the Flora of British Columbia [online]. Univ.

Brit. Col., Vancouver, BC. Available from: http://www.eflora.bc.ca [accessed 12 June 2017]. 


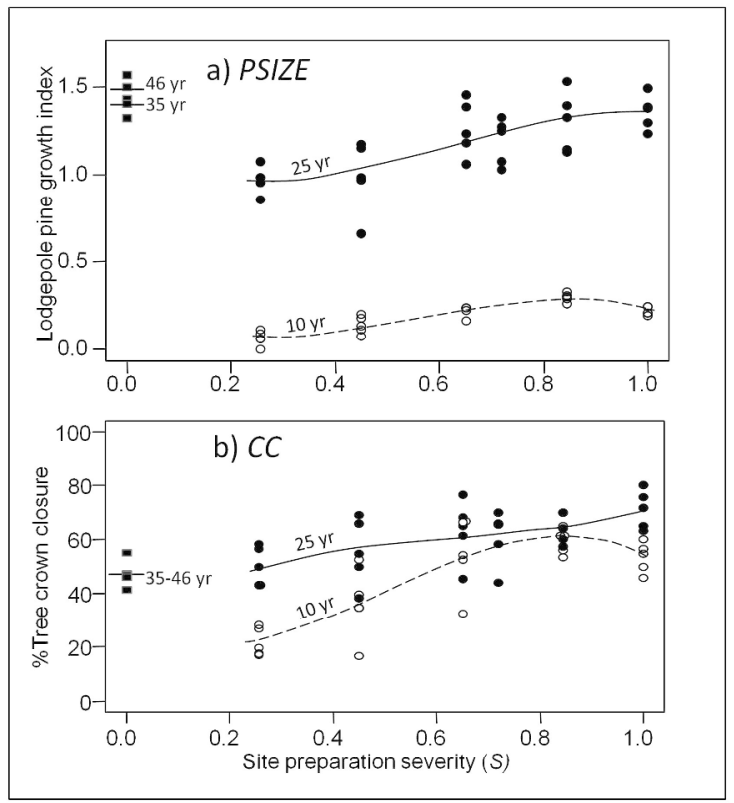

Figure 1

Best-fitting models for the relationship between site preparation severity $(S)$ and (a) pine size $(P S I Z E)$ and (b) percent crown closure of all tree species $(C C)$ (details in Tables 1, 2i). Unfilled circles, black circles and black squares represent 10-, 25- and 35-46-yr-old plots, respectively.

$254 \times 190 \mathrm{~mm}(300 \times 300 \mathrm{DPI})$ 


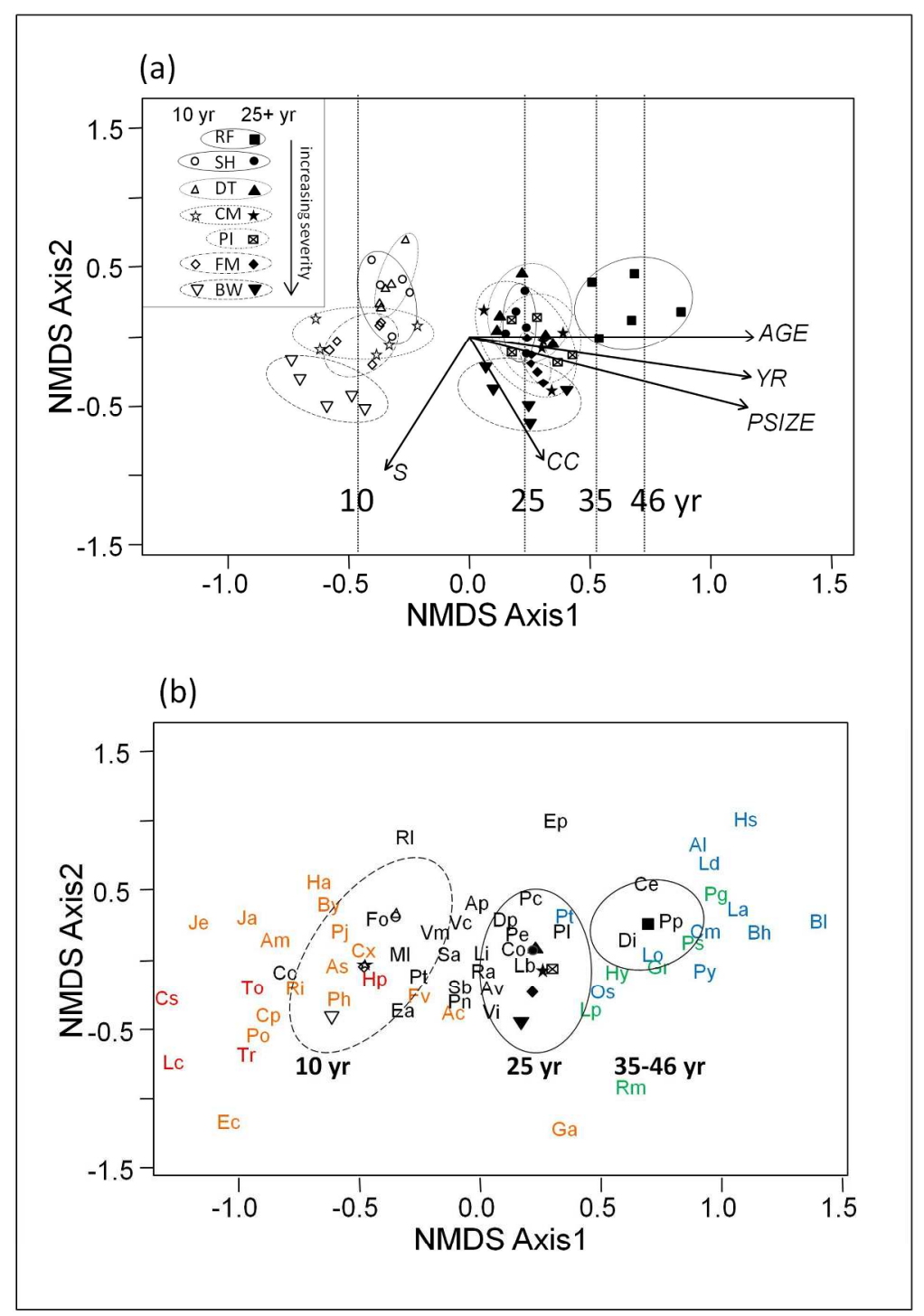

First two axes of a non-metric multi-dimensional scaling (NMDS) ordination of plant community composition of (a) Bednesti treatment plots with overlain explanatory variables (Table 1a). Vertical lines indicate midpoints for samples of a given stand age. (b) Ordination of plant taxa that are common or strongly associated with the NMDS axes (label colour indicates seral stage: red = early, black = generalist, blue = late, green $=$ epiphytic lichen; names in Table A-1). Ellipses outline location of 10- , 25-, and 35-46-yr old plots with symbols from (a) indicating centroids for each treatment.

$190 \times 254 \mathrm{~mm}(300 \times 300 \mathrm{DPI})$ 


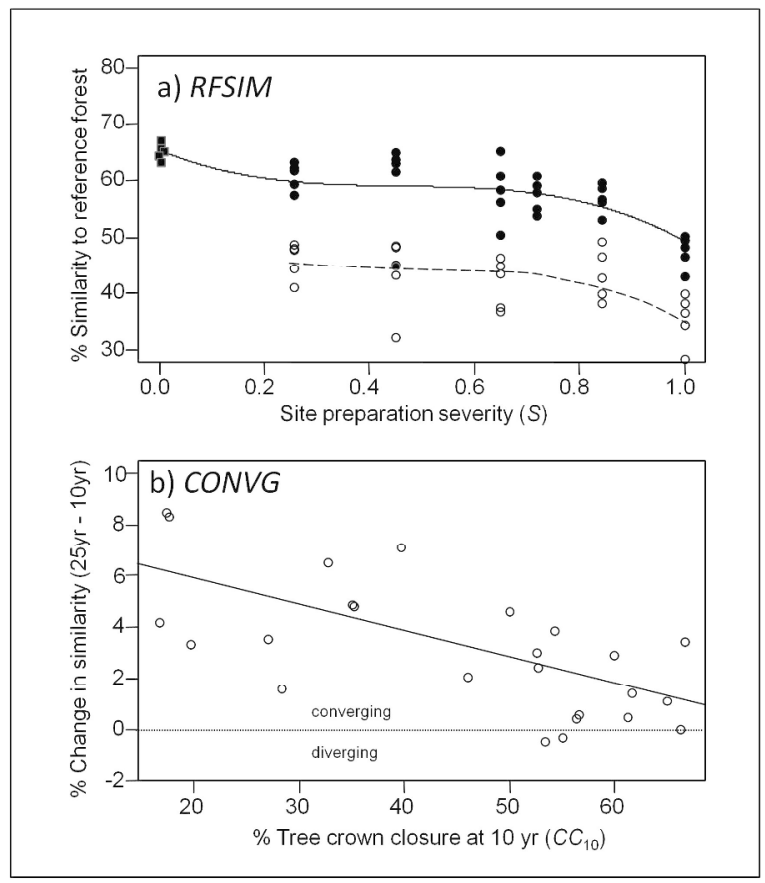

Figure 3

Best-fitting models for plant community composition response variables (a) RFSIM and (b) CONVG (described in Tables 1b, 2ii). In (a), unfilled circles and the dashed line depict 10-yr response; black symbols and the solid line depict 25+-yr response (square symbols compare each reference forest plot to 4 other reference forest plots). In (b), unfilled symbols and the solid line depict the mean change in community similarity between 1997 and 2012 with plots above the dotted line converging in composition, those below diverging, relative to all other plots.

$254 \times 190 \mathrm{~mm}(300 \times 300 \mathrm{DPI})$ 


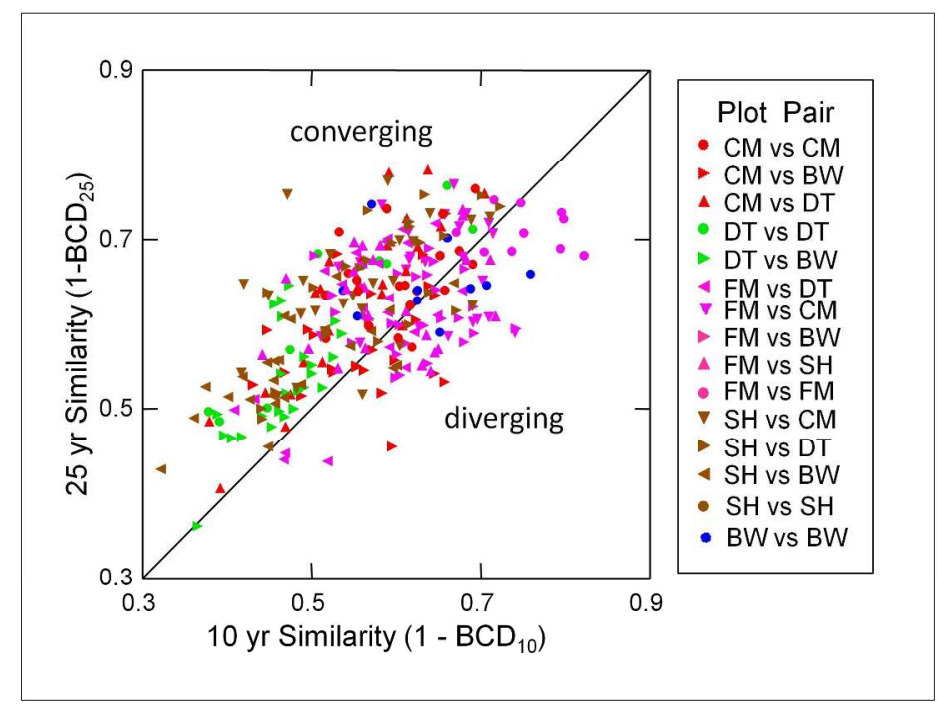

Figure 4

Similarity in plant species composition at $25 \mathrm{yr}$ plotted against similarity at $10 \mathrm{yr}$ for all pairs of plots sampled in both years (SH, DT, CM, FM, BW treatments). The diagonal line separates plot pairs that are converging between the two dates from plot pairs that are diverging. Symbols identify treatments for each plot pair.

$254 \times 190 \mathrm{~mm}(300 \times 300$ DPI $)$ 


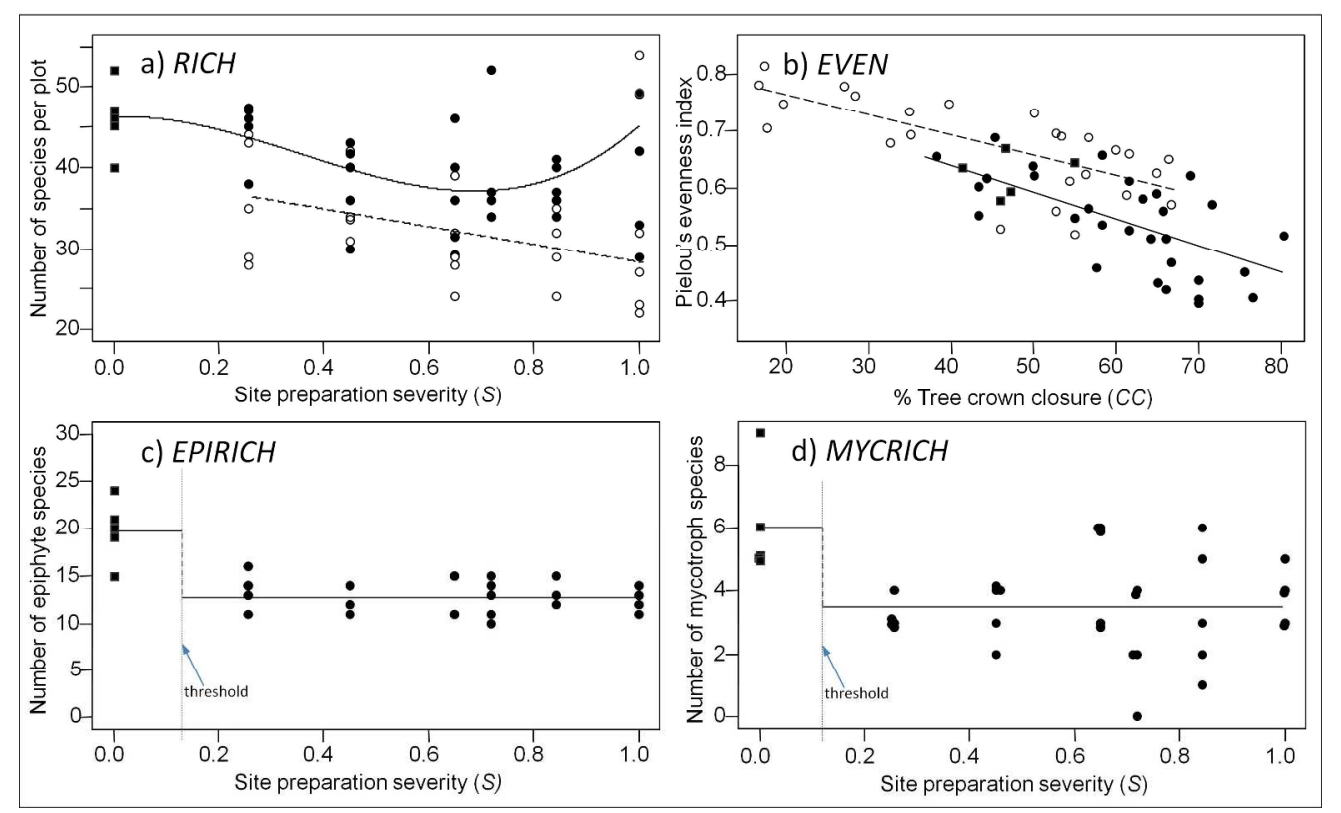

Figure 5

Best fitting models for species diversity response variables (a) species richness; (b) species evenness; (c) epiphyte species richness; (d) mycotroph species richness (details in Tables 1b, 2iii). Unfilled circles, black circles and black squares represent 10-, 25-and 35-46-yr-old plots, respectively. Dashed lines predict 10-yr response; solid lines predict 25- to 46-yr response; dotted vertical lines in (c) and (d) indicate low severity thresholds.

$254 \times 190 \mathrm{~mm}(300 \times 300$ DPI $)$ 


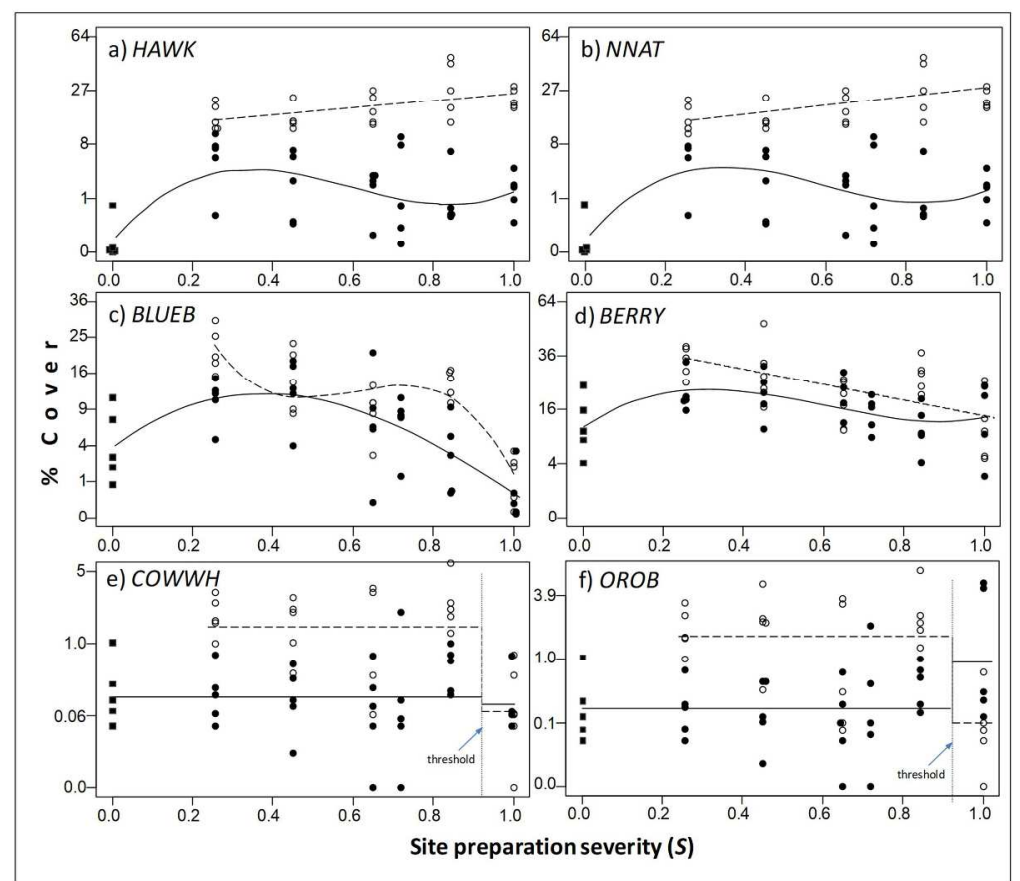

Best fitting models predicting abundance of (a) Pilosella hawkweeds; (b) all non-native plants; (c) velvetleaved blueberry; (d) all berry-producers; (e) cow-wheat; (f) all Orobanchaceae (details in Tables 1b, 2iv). Unfilled circles, black circles and black squares represent 10-, 25- and 35-46-yr-old plots, respectively. Dashed lines predict 10-yr response; solid lines predict 25- to 46-yr response; dotted vertical lines in (e) and (f) indicate high severity thresholds.

$254 \times 190 \mathrm{~mm}(300 \times 300$ DPI $)$ 


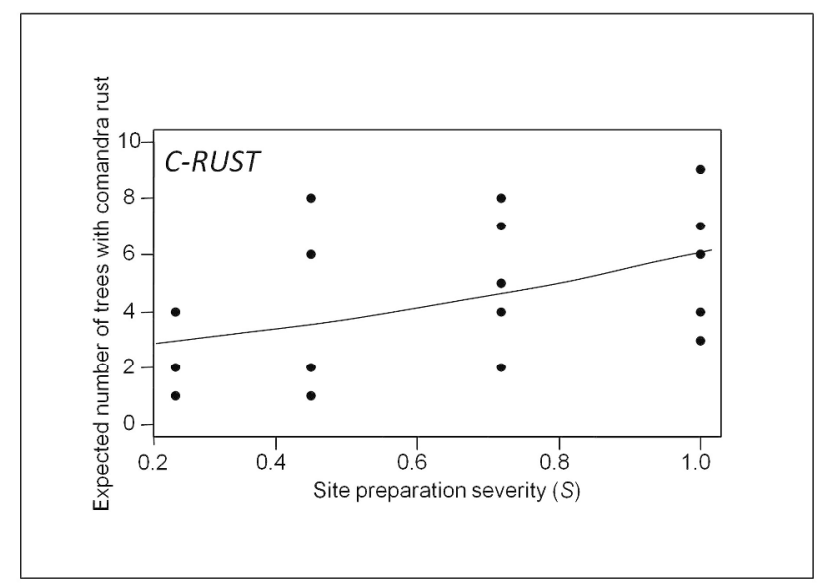

Figure 7

Best-fitting poisson model predicting the cumulative number of pine trees infected by Comandra blister rust per plot between 1994 and 2012 (details in Tables 1b, 2iv).

$254 \times 190 \mathrm{~mm}(300 \times 300$ DPI $)$ 